\title{
A theoretical model of neural maturation in the developing chick spinal cord
}

\author{
Piyush Joshi ${ }^{1}$, Isaac Skromne $\oplus^{2 *}$ \\ 1 Division of Pediatric Neuro-oncology, German Cancer Research Center (DKFZ), Heidelberg, Germany, \\ 2 Department of Biology, University of Richmond, Richmond, Virginia, United States of America \\ * iskromne@ richmond.edu
}

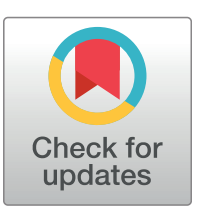

\section{G openaccess}

Citation: Joshi P, Skromne I (2020) A theoretical model of neural maturation in the developing chick spinal cord. PLOS ONE 15(12): e0244219. https:// doi.org/10.1371/journal.pone.0244219

Editor: Allan R. Martin, University of California, Davis, UNITED STATES

Received: July 21, 2020

Accepted: December 4, 2020

Published: December 18, 2020

Peer Review History: PLOS recognizes the benefits of transparency in the peer review process; therefore, we enable the publication of all of the content of peer review and author responses alongside final, published articles. The editorial history of this article is available here: https://doi.org/10.1371/journal.pone.0244219

Copyright: ๑ 2020 Joshi, Skromne. This is an open access article distributed under the terms of the Creative Commons Attribution License, which permits unrestricted use, distribution, and reproduction in any medium, provided the original author and source are credited.

Data Availability Statement: All relevant data are within the manuscript and its Supporting Information files.

Funding: P.J. was supported by Sigma XI GIAR, and I.S. was supported by University of Richmond School of Arts and Sciences and by the National

\section{Abstract}

Cellular differentiation is a tightly regulated process under the control of intricate signaling and transcription factors interaction network working in coordination. These interactions make the systems dynamic, robust and stable but also difficult to dissect. In the spinal cord, recent work has shown that a network of FGF, WNT and Retinoic Acid (RA) signaling factors regulate neural maturation by directing the activity of a transcription factor network that contains CDX at its core. Here we have used partial and ordinary (Hill) differential equation based models to understand the spatiotemporal dynamics of the FGF/WNT/RA and the $\mathrm{CDX} /$ transcription factor networks, alone and in combination. We show that in both networks, the strength of interaction among network partners impacts the dynamics, behavior and output of the system. In the signaling network, interaction strength determine the position and size of discrete regions of cell differentiation and small changes in the strength of the interactions among networking partners can result in a signal overriding, balancing or oscillating with another signal. We also show that the spatiotemporal information generated by the signaling network can be conveyed to the CDX/transcription network to produces a transition zone that separates regions of high cell potency from regions of cell differentiation, in agreement with most in vivo observations. Importantly, one emerging property of the networks is their robustness to extrinsic disturbances, which allows the system to retain or canalize NP cells in developmental trajectories. This analysis provides a model for the interaction conditions underlying spinal cord cell maturation during embryonic axial elongation.

\section{Introduction}

Cells sequentially differentiate from high to low potency states, under the guidance of extracellular signals working in coordination with intracellular transcription factors. Signals regulate the individual and network activity of the transcription factors by providing spatial and temporal information [1-4]. In turn, transcriptional network dictates a cell's competence and response to extracellular signals [5-7]. Because signaling information changes the composition of a cell's transcriptional components, this creates an intricate and dynamic cross-regulatory system for guiding cell differentiation that has been challenging to untangle and comprehend $[1,3,4]$. Understanding the cross-regulatory interactions between signal and transcription 
Science Foundation (IOS-1755386). The funders had no role in study design, data collection and analysis, decision to publish, or preparation of the manuscript.

Competing interests: The authors have declared that no competing interests exist. factor sub-networks will be important for understanding to how cell trajectories are retained during development in the face of genetic or environmental perturbations (canalization; [8])

Vertebrate spinal cord provides an advantageous model to study the cross-regulatory dynamics involved in central nervous system development in particular, and differentiation in general. The head (rostral) to tail (caudal) development of spinal cord during vertebrate body extension results into a characteristic spatial separation of temporal differentiation events [9-11], facilitating the study of their regulation. Experimental data obtained from mouse, chick and zebrafish embryos support a model in which spinal cord neural progenitors (NPs) are derived from a bipotent population of cells located at the caudal most end of the embryo, the neuro-mesodermal progenitors (NMPs) cells $[9,10]$. In the early embryo, the region where NMPs reside is known as the caudal lateral epiblast and node streak border, and once the tailbud has formed in the late embryo (in chick between 16-22 somite stage; [12, 13]), the caudal neural hinge [9-11]. During development, NP cells exit the NMP domain rostrally and then, sequentially, transit through different maturation states as they become part of the spinal cord $[9,14,15]$.

NP cell maturation is driven by synergistic and antagonistic interactions between the signaling factors FGF, WNT and Retinoic Acid (RA), turning on and off key transcription factors required for caudal-to-rostral maturation events (Fig 1A). In the chick trunk region of the spinal cord (somites 6-18), two opposite signaling gradients are proposed to regulate spinal cord cell maturation [16]: from caudal/high to rostral/low, FGF and WNT gradients prevent cell differentiation by promoting high potency cell states caudally; whereas an opposite rostral/ high to caudal/low gradient of RA secreted from somites promotes cell differentiation rostrally. Importantly, FGF and WNT activity gradient counteract RA activity gradient. In this way, NMP cells located caudally experience high levels of FGF/WNT and no RA, which drives expression of bipotency markers T/Bra, Sox2, and Nkx1.2 (Sax1) [16-18]. T/BRA and SOX2 are transcription factors that repress each other and promote different cell fates, with T/BRA promoting mesoderm and SOX2 promoting neural fates [17-19], a phenomenon extensively documented in mouse [20-23]. In addition, both T/BRA and SOX2 can downregulate FGF and WNT pathway activity, initiating the early differentiation of mesoderm or neural tissues [20]. NMPs that continue to transcribe Sox 2 but not T/Bra assume NP identity and become part of the growing neural plate. As NPs transit through the maturing neural plate, they experience a further gradual loss in FGF and WNT, and a gradual increase in RA signaling. This new environment lead to the caudal-to-rostral downregulation of a third bipotency marker, Nkx1.2, and upregulation of the early differentiation gene Pax6 [24]. Subsequently, under RA regulation, PAX6 activates late differentiation genes such as $\mathrm{Ngn} 2$ (Fig 1B) $[25,26]$. Recently, we have experimentally mapped the interactions between $T / B r a$, Sox2, Nkx1.2, Cdx4, Pax6 and $\mathrm{Ngn} 2$ into a gene regulatory network (GRN) that we placed it in the context of the FGF/ WNT-RA signaling network (Fig 1C) [15]. This work identified the transcription factor CDX4 as a core system component essential for the sequential maturation of NPs into mature neuronal precursors (Fig 1C).

Here we use partial and ordinary (Hill) differential equations to dynamically analyze the GRN driving NP cell maturation during early chick spinal cord development (10-18 somite stage). As the transcription factor network depends upon inputs form the FGF-WNT-RA signaling network, we first analyzed the postulated effectiveness of the signaling network to work as a signaling switch [27]. We then used the resulting signaling dynamics as input to evaluate the performance of the underlying transcription GRN in its ability to generate cell state patterns similar to those observed in experimental models. Our results show that signaling interaction can give rise to various developmentally observed phenotypes based on a limited subset of interaction parameters, and these behaviors are robust and stable to perturbations. Network robustness is a property emerging from strong cross-regulation interactions between 
A

C
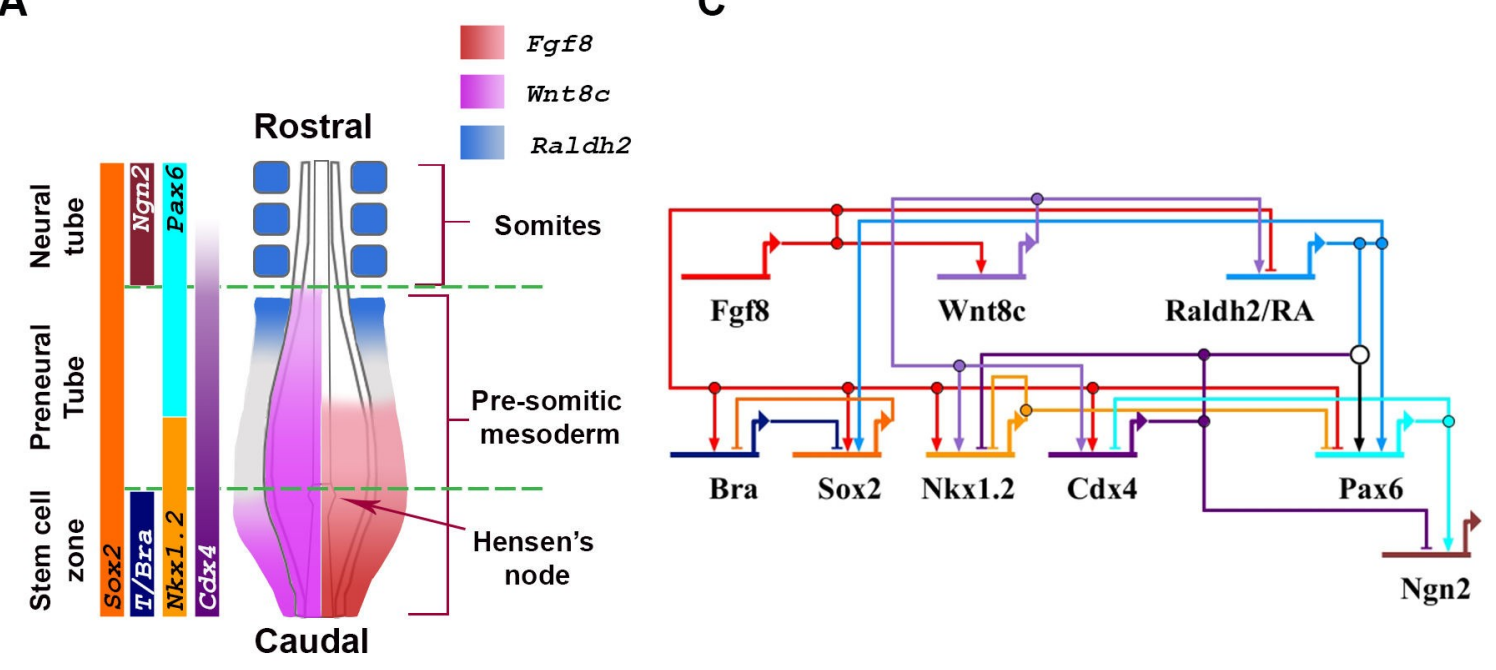

B
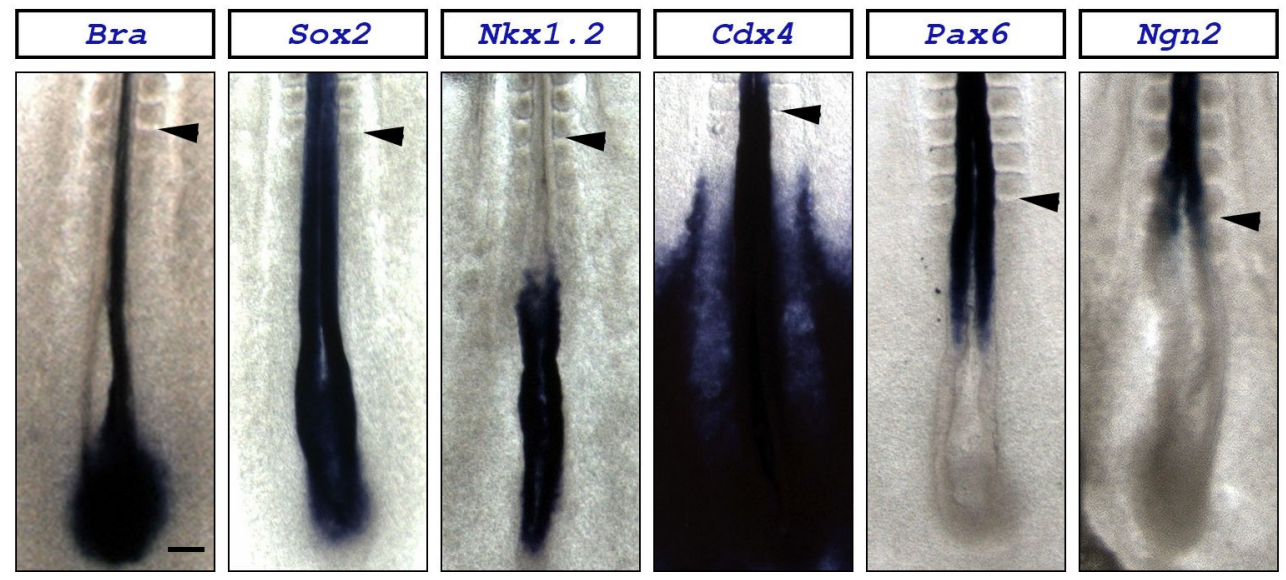

Fig 1. Expression domains and network interactions of key signaling and transcription factors involved in caudal spinal cord maturation. (A) Schematic representation of the caudal end of a stage HH10-11 chick embryo (dorsal view). Expression domains of Fgf8 (red) and Wnt8c (magenta) signaling factors, and the Retinoic Acid synthesizing enzyme Raldh2 (blue), are superimposed on the diagram (based on [27]). Expression domain of relevant transcription factors are indicated on the left (based on [15]). (B) Expression domains of key transcription factors involved in caudal spinal cord maturation. Embryos are stage HH10-11. Scale bar is $200 \mu \mathrm{m}$. Arrowheads indicates the anterior boundary of the last formed somite. Transcription of the T/Bra gene along the embryo's midline is in the notochord underlying the neural tissue, where it is absent. (C) Postulated gene regulatory network showing interaction between signaling and transcription factors (based on $[15,20,25,27]$ ).

https://doi.org/10.1371/journal.pone.0244219.g001

individual system components whose function we propose is to canalize the cells in their NP trajectories. Our results suggests that the dominant predictor of the GRN response is the interaction strength among network partners. By outlining the conditions that permit the operation of the GRN during NP maturation in silico, the model predicts and informs on cellular behaviors of the system in vivo.

\section{Materials and methods}

\section{Chick embryos, gene expression analysis and ethics statement}

Fertile broiler chicken eggs (Morris Hatchery, Inc.; Miami, FL) were incubated to the 10-somite stage of development before embryos were processed for expression analysis (about 
35 hours at $38^{\circ} \mathrm{C}$ in a humid chamber). Expression analysis of relevant genes was done as previously reported (see S1 File; [15]). Chick embryos younger than three days, such as the ones used in this study, are considered by The American Association for Laboratory Animal Sciences (AALAS) and the American Veterinary Medical Association (AVMA), incapable of feeling pain. Therefore, this study is exempt of Institutional Animal Care and Use Committees (IACUC) review.

\section{Model outline}

Our model aims to describe the maturation of NP cells in the pre-neural tube region of chick embryos between 10-18 somite stage using previously published empirical data [15]. This time period was selected for several reasons. First, the average velocity of axial elongation (2.5$3 \mu \mathrm{m} / \mathrm{min}$ ) and the size pre-neural tube region ( 2500 microns) are relatively consistent (measured from the caudal lateral epiblast where the NMPs reside to where the neural tube closes at the anterior boundary of the last formed somite) [28]. Second, most parametric values required by the model are available for the chick embryo, and the few missing ones can be extrapolated from mouse or cell culture data (described in detail below). Third, the only $C d x$ family member transcribed in the chick embryo between 10-18 somite stage is $C d x 4$ [29]. Finally, we could overlook GDF11 activity in terminating axial elongation, as this activity in mouse is associated with the relocation of NMP from the caudal primitive streak epiblast to the tail bud [30,31], which in chicks occurs after the stages our simulation models (16-22 somite stage; [13]). In addition, our model assumes that NP production to occur at a steady rate, independently of any network components. This is not the case in vivo, were experimental evidence suggests an involvement of $\mathrm{NOTCH}$ signaling pathway in this process [32, 33]. This assumption was made due to paucity of evidence connecting NOTCH regulation to $C d x 4$ and many of the transcription factors in the GRN.

\section{Hill equation based interaction model}

Signal and transcription factor networks were modeled using ordinary and partial differential Hill equations. Ordinary differential Hill equations were used to model molecules whose rate of change is not influenced by diffusion (e.g., mRNA and intracellular proteins), and partial differential Hill equations for molecules whose rate of change in a field is contingent on their diffusion (e.g., extracellular factors) [34-36]. We first modeled the signal interactions network, using the resulting output as the input for the transcription factor network. To solve the equations numerically and plot the simulations we used MATLAB (MathWorks, Natick, MA) with solvers ode 45 for ordinary and pdepe for partial differential equations. Within each Hill equation, a number of Hill constants were used to vary the strength of interaction between a molecule and its target (e. g., transcription factor and its target gene; S1 Fig). These equations follow the general form;

Ordinary differential equation to model mRNA dynamics:

$$
\frac{\partial M}{\partial t}=\alpha_{m} H_{1}-\beta_{m} M H_{2}
$$

Ordinary differential equation to model intracellular protein dynamics (e.g., transcription factors):

$$
\frac{\partial P}{\partial t}=\alpha_{p} M H_{3}-\beta_{p} P H_{4}
$$


Partial differential equations to model dynamics of extracellular factors (e.g., signaling molecules):

$$
\frac{\partial P}{\partial t}=\alpha_{p} M H_{3}-\beta_{p} P H_{4}-\mu \frac{\partial \mathrm{P}}{\partial x^{2}}
$$

where,

$\alpha_{m}=$ Transcription rate constant $\alpha_{p}=$ Translation rate constant

$\beta_{m}=$ mRNA decay rate constant $\beta_{p}=$ protein decay rate constant

$M=$ mRNA concentration $P=$ protein concentration

$\mu=$ diffusivity coefficient $x=$ spatial dimension

$H_{1}, H_{2}, H_{3}, H_{4}$ are independent Hill functions. For each factor being modeled, we replaced $\mathrm{H}_{1}, \mathrm{H}_{2}, \mathrm{H}_{3}$, and $\mathrm{H}_{4}$ with one of four general types of functions representing regulatory interaction observed in vivo (see S1 File): (1) inductive interactions from one or multiple activators, (2) repressive interactions from one or multiple repressors, (3) coordinated interactions between activators and repressors binding to separate regulatory sites and (4) competitive interactions between activators or repressors binding to the same regulatory sites.

\section{Equations modeling the signaling interactions network}

Partial differential Hill equations that take diffusion into consideration were used to model FGF8, WNT8C and RA network of interactions (Fig 2A). These interactions were modeled within a spatial maturation domain restricted to a 2500 microns extending from the NMP zone to the anterior boundary of the last formed somite (stage HH10-11 embryos; Figs 1B and 2B). This spatial maturation domain moves caudally and in synchrony with the NMP zone during axial elongation (constant velocity), thus appearing stationary with respect to the NMP zone (Fig 2B). When available, we used parameter values that have been determined experimentally, within reported ranges. For parameters that have not been determined experimentally (e.g., rates constants for mRNA and protein synthesis and degradation), we used parameters values comparable to those used in other models [28, 37, 38]. We set the Hill coefficients value for FGF and Wnt at 2, as empirically established in somitogenesis network model [37]. For RA, the value of the Hill coefficient factor was set at 2, as RA's receptor is a transcription factor that operates as a dimer [39].

FGF8 production. Fgf8 transcription is restricted to the NMP zone through positive autoregulatory loops and inhibitory signals [40]. FGF8 indirectly stimulates its own transcription by inducing transcription of $N k x 1.2, C d x$, and WNT/B-catenin pathway components [40]. RA secreted from somites restricts $F g f 8$ to the NMP zone in a concentration-dependent manner [16]. RA inhibition is excluded from NMP zone by CYP26A, an RA-catabolizing enzyme whose gene is activated by FGF8 [18]. We simulated F $g 8$ positive autoregulatory loop by assuming a basal exponential level of gene transcription, and its restriction to the caudal end of the spatial maturation domain by allowing RA to decrease $F g f 8$ transcription down to zero in a concentration-dependent manner.

Fgf 8 mRNA transcripts have a long half-life of around 2 hours, persisting in cells long after transcription has stopped $[37,41]$. This long decay results in a graded distribution of transcript in the spatial maturation domain, with cells proximal to the NMP zone retaining more transcripts that more distal cells. This 2 hour half-life sets the rate constant of degradation to around 0.006 $\min ^{-1}(\ln 2 / 2 \mathrm{~h}=0.693 / 120 \mathrm{~min})$. As the average speed of axis elongation is $2.5-3 \mu \mathrm{m} / \mathrm{min}$ (from somite 5 to 18; [28]), the decay constant in the spatial maturation domain is about $0.002 \mu \mathrm{m}^{-1}$.

FGF8 protein synthesis is dependent on the concentration of the Fgf8 transcript within each cell. As FGF8 is synthesized, it diffuses from producing cells at a rate that has been 
A

B
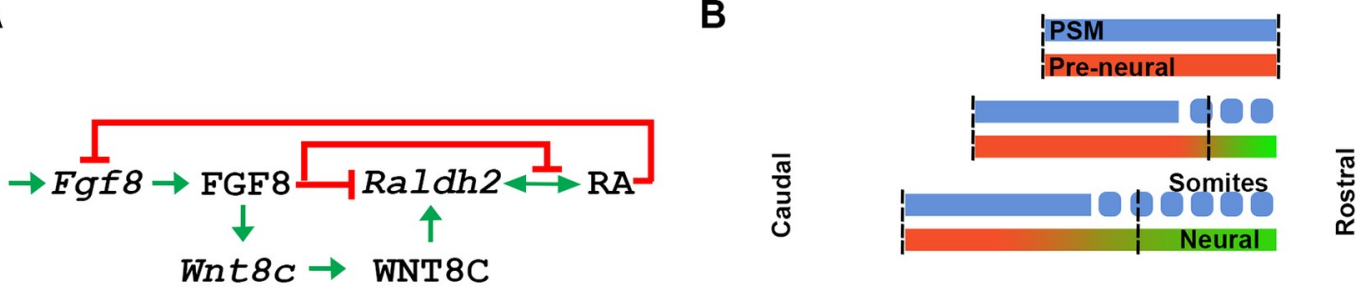

1000000

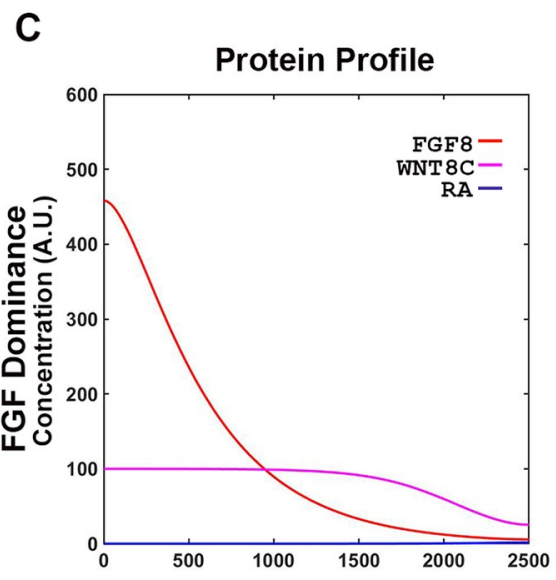

D

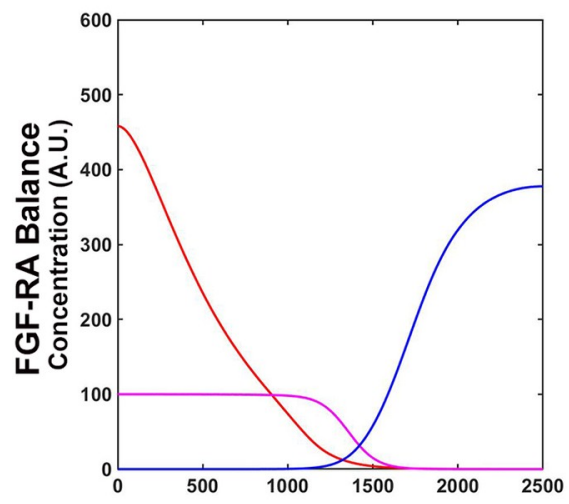

E

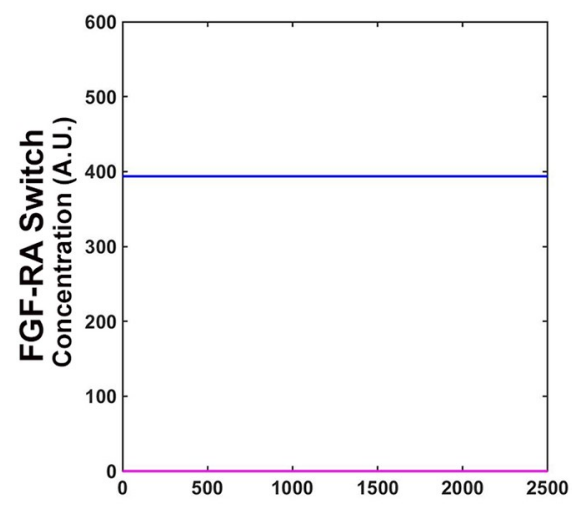

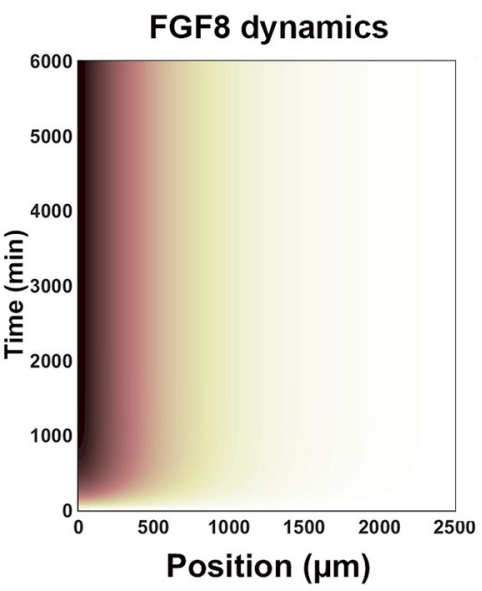
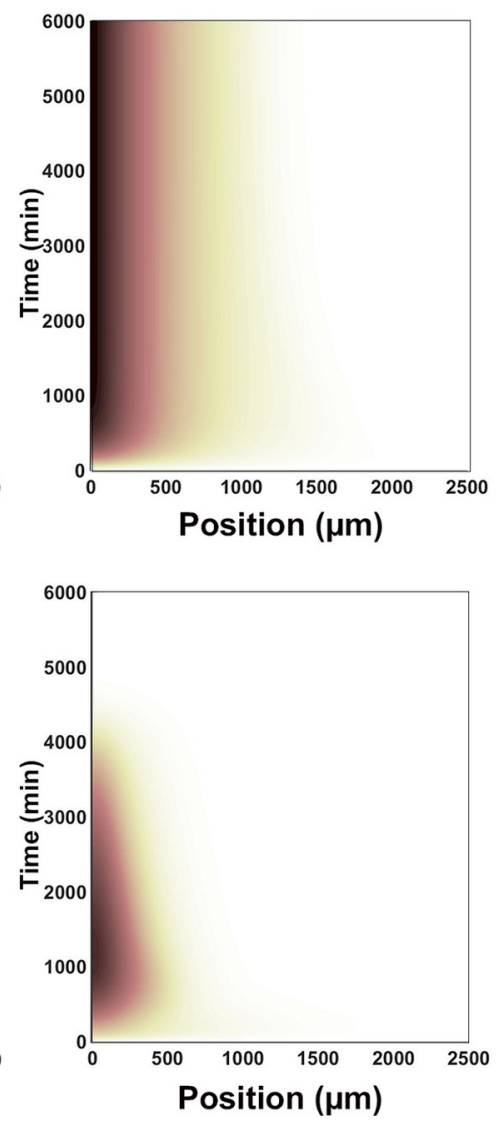
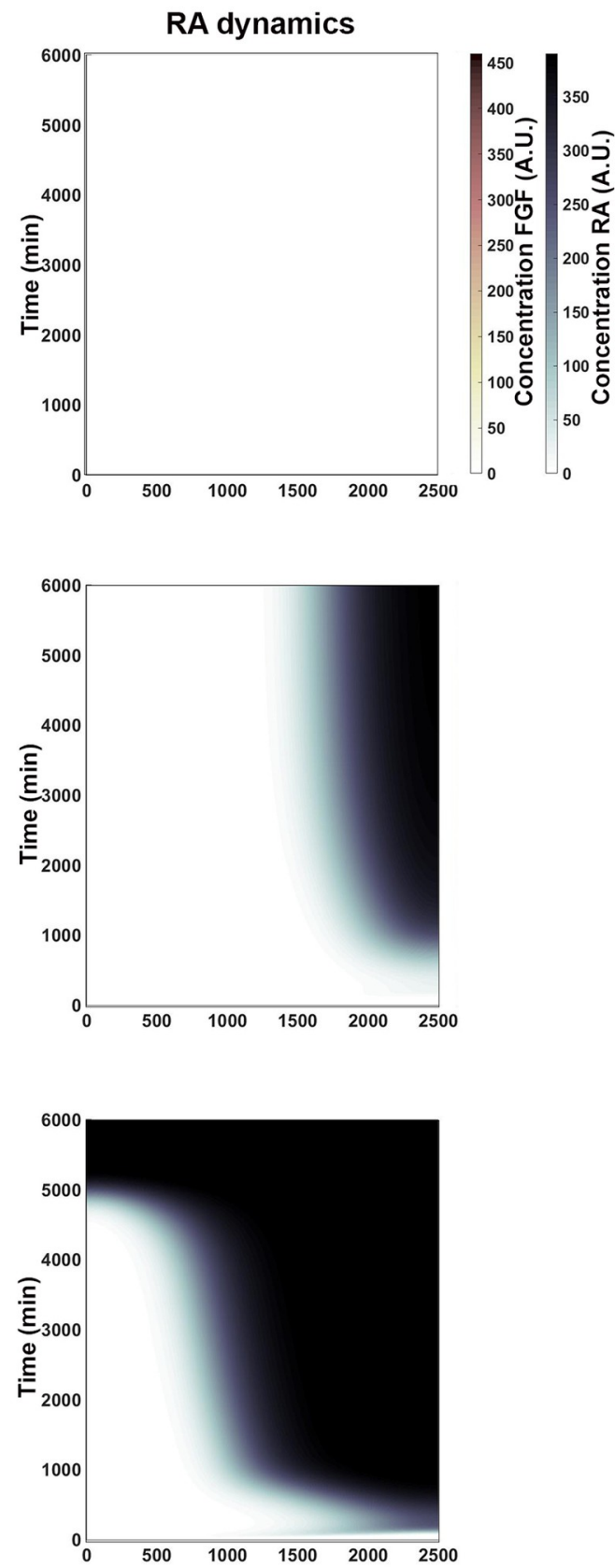
Fig 2. Signaling network output is determined by the strength of interactions between FGF, WNT, and RA pathway components. (A) FGF8, WNT8C and RA signaling pathway interaction network based on [27]. Names in lower case indicate mRNA and upper case proteins (FGF8 and WNT8C) or metabolites (RA). (B) The spatial maturation domain where the signaling network operates extends from the NMP cells to the anterior boundary of the last formed somite (vertical dashed lines; $\mathrm{X}$-axes on graphs). The domain in the simulation has a constant length maintained by a caudal movement that is equivalent to the rate of NMP cell proliferation. Initially undifferentiated cells differentiate at a rate defined by the simulation (red to green transition). (C-E) Representative FGF8 dominant (C), FGF-RA balance (D), and FGF-RA switch (E) simulation profiles obtained using parameters shown in Table 1. Left graphs shows the levels of the signaling molecules FGF8 (red), WNT8C (magenta) and RA (blue) across the maturation domain at the end of the simulation ( $\mathrm{t}=6000 \mathrm{~min}$; arbitrary units $\mathrm{AU}$ ). Center and right graphs show heat maps of FGF8 (center) and RA (right) accumulation in the maturation domain (x-axis) over time (y-axis). AU scale for FGF (maroon gradient) and RA (blue gradient) are shown at right of graphs.

https://doi.org/10.1371/journal.pone.0244219.g002

determined experimentally to be around $2 \mu \mathrm{m}^{2} / \mathrm{sec}$ [42]. Due to this diffusion, the domain of FGF protein signaling expands beyond the domain of $F g f 8$ transcription.

Constant input: $F_{0}(x)$

$$
F_{0}=0.06 e^{-.002 x}
$$

Fgf8 mRNA transcription: $F_{m}(t)$

$$
\frac{\partial F_{m}}{\partial t}=\alpha_{F m} F_{0}\left(\frac{1}{\left(1+\left(R / R_{F R}\right)^{r}\right)}\right)-\beta_{F m} F_{m}
$$

FGF8 translation: $F(x, t)$

$$
\frac{\partial F}{\partial t}=\alpha_{F P} F_{m}-\beta_{F p} F-D_{F} \frac{\partial^{2} F}{\partial x^{2}}
$$

where,

Fgf 8 mRNA transcription rate constant $[37,38] \alpha_{F m}=1 / \mathrm{min}$

Fgf8 mRNA half-life [37] $\beta_{F m}=0.006 / \mathrm{min}$.

FGF8 translation rate constant [37] $\alpha_{F p}=0.3 / \mathrm{min}$

FGF8 degradation rate constant [37] $\beta_{F p}=0.005 / \mathrm{min}$

FGF8 diffusion constant [42] $D_{F}=120 \mu \mathrm{m}^{2} / \mathrm{min}$

Hill constant, Fgf 8 inhibition by RA $R_{R F}$ (see Table 1)

WNT8C production. Wnt $8 \mathrm{c}$ transcription is stimulated by FGF pathway activity and is

\begin{tabular}{|c|c|c|c|c|c|c|c|c|}
\hline Hill constants & I & II & III & IV & $\mathbf{V}$ & VI & VII & VIII \\
\hline $\mathrm{F}_{\mathrm{FW}}$ & \multirow[t]{2}{*}{10} & \multirow[t]{2}{*}{10} & \multirow[t]{2}{*}{10} & \multirow[t]{2}{*}{10} & \multirow[t]{2}{*}{10} & \multirow[t]{2}{*}{10} & \multirow[t]{2}{*}{10} & \multirow[t]{2}{*}{10} \\
\hline FGF dependent activation of $W n t 8 c$ transcription & & & & & & & & \\
\hline $\mathrm{F}_{\mathrm{FR} 1}$ & \multirow[t]{2}{*}{1} & \multirow[t]{2}{*}{1} & \multirow[t]{2}{*}{5} & \multirow[t]{2}{*}{10} & \multirow[t]{2}{*}{10} & \multirow[t]{2}{*}{10} & \multirow[t]{2}{*}{2} & \multirow[t]{2}{*}{20} \\
\hline FGF dependent repression of Raldh2 transcription & & & & & & & & \\
\hline$\underline{\mathrm{F}_{\mathrm{FR} 2}}$ & \multirow[t]{2}{*}{2} & \multirow[t]{2}{*}{10} & \multirow[t]{2}{*}{15} & \multirow[t]{2}{*}{10} & \multirow[t]{2}{*}{10} & \multirow[t]{2}{*}{10} & \multirow[t]{2}{*}{20} & \multirow[t]{2}{*}{20} \\
\hline FGF dependent activation of RA degradation (via CYP26A enzymes) & & & & & & & & \\
\hline $\mathrm{W}_{\mathrm{WR}}$ & \multirow[t]{2}{*}{1} & \multirow[t]{2}{*}{1} & \multirow[t]{2}{*}{0.2} & \multirow[t]{2}{*}{0.5} & \multirow[t]{2}{*}{0.2} & \multirow[t]{2}{*}{0.5} & \multirow[t]{2}{*}{1} & \multirow[t]{2}{*}{1} \\
\hline WNT dependent activation of Raldh 2 transcription & & & & & & & & \\
\hline $\mathrm{R}_{\mathrm{RF}}$ & \multirow[t]{2}{*}{10} & \multirow[t]{2}{*}{1} & \multirow[t]{2}{*}{0.2} & \multirow[t]{2}{*}{0.1} & \multirow[t]{2}{*}{0.3} & \multirow[t]{2}{*}{0.45} & 1 & 20 \\
\hline RA dependent repression of $F g f 8$ transcription & & & & & & & & \\
\hline $\mathrm{R}_{\mathrm{RR}}$ & 50 & 50 & 50 & 50 & 50 & 50 & 300 & 300 \\
\hline RA dependent activation of Raldh2 transcription & & & & & & & & \\
\hline Outcome $(t=6000 \mathrm{~min})$ & FGF dominant & FGF-RA balance & & FGF- & switc & & $\begin{array}{l}\text { RA } \\
\text { osc }\end{array}$ & $\begin{array}{l}\text { rrant/ } \\
\text { tory }\end{array}$ \\
\hline
\end{tabular}
indirectly blocked by RA inhibiting Fgf 8 transcription [27]. In chick embryos, Wnt8c

Table 1. Examples of Hill constants combinations tested to investigate signaling dynamics behavior.

https://doi.org/10.1371/journal.pone.0244219.t001 
expression domain significantly overlaps and extends far beyond $F g f 8$ mRNA domain up to the last formed somite (Fig 1A; $[27,43]$ ), suggesting that very low levels of FGF8 can activate $W n t 8 c[27,43]$. By contrast, in the NMP zone, Wnt8c mRNA level are one-third of the Fgf8 mRNA level [44], which suggest that transcription rate constant of $W n t 8 c$ are low and saturate quickly [44]. Once synthesized, WNT8C diffuse from its site of synthesis throughout the spatial maturation domain at a low diffusion rate [45].

Wnt $8 c$ mRNA transcription: $W_{m}(t)$

$$
\frac{\partial W_{m}}{\partial t}=\alpha_{W m}\left(\frac{\left(F / F_{F W}\right)^{a}}{\left(1+\left(F / F_{F W}\right)^{a}\right)}\right)-\beta_{W m} W_{m}
$$

WNT8C translation: $W(x, t)$

$$
\frac{\partial W}{\partial t}=\alpha_{W p} W_{m}-\beta_{W p} W-D_{W} \frac{\partial^{2} W}{\partial x^{2}}
$$

, where,

Wnt8c mRNA transcription rate constant $[27,43] \alpha_{W m}=0.1 / \mathrm{min}$

Wnt $8 c$ mRNA half-life constant $[27,43] \beta_{W m}=0.03 / \mathrm{min}$

WNT8C translation rates constant [37] $\alpha_{W p}=0.3 / \mathrm{min}$

WNT8C degradation rates constant [37] $\beta_{W p}=0.01 / \mathrm{min}$

WNT8C diffusion rate rates [45] $D_{W}=10 \mu \mathrm{m}^{2} / \mathrm{min}$

Hill constant, Wnt $8 c$ activation by FGF8 $F_{F W}$ (see Table 1)

RA production. RA is synthesized in somites by the enzyme RALDH2 [46]. Raldh2 transcription is restricted to somites as this is the only region where activation by the WNT8C pathway can overcome FGF8-dependent repression [27]. Parameters for RALDH2 production and degradation were equivalent to those in other models [47]. We assumed that once RALDH2 is produced, RA synthesis initiates without delay. Once produced, RA diffuses into undifferentiated neural and mesodermal tissues at an estimated rate of $18 \mu \mathrm{m}^{2} / \mathrm{sec}$ or about $1080 \mathrm{\mu m}^{2} / \mathrm{min}$ [47]. At the caudal end of the embryo, RA is degraded by the enzyme CYP26A, whose transcription is under FGF8 regulation [25].

Raldh2 mRNA transcription: $R_{m}(t)$

$$
\frac{\partial R_{m}}{\partial t}=\alpha_{R m}\left(\frac{\left(W / W_{W R}\right)^{a}+\left(R / R_{R R}\right)^{a}}{\left(1+\left(W / W_{W R}\right)^{a}+\left(R / R_{R R}\right)^{a}\right)}\right)\left(\frac{1}{\left(1+\left(F / F_{F R 1}\right)^{r}\right)}\right)-\beta_{R m} R_{m}
$$

RA production (as modeled by RALDH2 translation): $R(x, t)$

$$
\frac{\partial R}{\partial t}=\alpha_{R p} R_{m}-\beta_{R p} R\left(1+\beta_{F R} \frac{\left(F / F_{F R 2}\right)^{a}}{\left(1+\left(F / F_{F R 2}\right)^{a}\right)}\right)-D_{R} \frac{\partial^{2} R}{\partial x^{2}}
$$

, where,

Raldh 2 mRNA transcription rate constant [37] $\alpha_{R m}=1 / \mathrm{min}$

Raldh2 mRNA half-life constant [37] $\beta_{R m}=0.03 / \mathrm{min}$

RALDH2 translation rates constant [37] $\alpha_{R p}=0.3 / \mathrm{min}$

RALDH2 degradation rates constant [37] $\beta_{R p}=0.025 / \mathrm{min}$

RA estimated diffusion rate $D_{R}=1200 \mu \mathrm{m}^{2} / \mathrm{min}$

FGF dependent RALDH2 degradation constant $\beta_{F R}=6 / \mathrm{min}$

Hill constant, Raldh2 induction by WNT8C $W_{W R}$ (see Table 1)

Hill constant, Raldh2 induction by RA (autoregulation) $R_{R R}$ (see Table 1)

Hill constant, Raldh 2 repression by FGF8 $F_{F R 1}$ (see Table 1)

Hill constant, RA degradation by FGF8-induced CYP26A $F_{F R 2}$ (see Table 1) 


\section{Equations modeling the transcription factors interactions network}

We used differential equations to simulate the transcription factor network (Fig 1C), as transcription factors do not diffuse outside the cell. As inputs, we used FGF8, WNT8C and RA output levels obtained in the signaling simulation (represented in the equations with the letters $\mathrm{F}$, $\mathrm{W}$ and $\mathrm{R}$, respectively). For transcription factors binding as dimers, the Hill coefficient was set to a value of 2 (T/BRA, SOX2, CDX4, PAX6 and NGN2; [48-52]), following other model's practices [37]. For simplicity, we also assumed a Hill coefficient value of 2 for transcription factors with no binding information (NKX1.2, X and Y). Network interactions described in the result section are supported by experimental evidence (reviewed in [15]).

T/Bra mRNA: $T_{m}(t)$

(Synthesis activated by FGF8 and inhibited by SOX2.)

$$
\frac{\partial T_{m}}{\partial t}=\alpha_{T m}\left(\frac{\left(F / F_{F T}\right)^{a}}{\left(1+\left(F / F_{F T}\right)^{a}+\left(S / S_{S T}\right)^{r}\right)}\right)-\beta_{T m} T_{m}
$$

T/BRA protein: $T(t)$

$$
\frac{\partial T}{\partial t}=\alpha_{T p} T_{m}-\beta_{T p} T
$$

Sox2 mRNA: $S_{m}(t)$

(Synthesis activated by FGF8 and RA and inhibited by T/BRA.)

$$
\frac{\partial S_{m}}{\partial t}=\alpha_{S m}\left(\frac{\left(F / F_{F S}\right)^{a}+\left(R / R_{R S}\right)^{a}}{\left(1+\left(F / F_{F S}\right)^{a}+\left(R / R_{R S}\right)^{a}+\left(T / T_{T S}\right)^{r}\right)}\right)-\beta_{S m} S_{m}
$$

SOX2 protein: $S(t)$

$$
\frac{\partial S}{\partial t}=\alpha_{S p} S_{m}-\beta_{S p} S
$$

$N k x 1.2$ mRNA: $N K_{m}(t)$

(Nkx1.2 is activated by WNT8C and inhibited by a CDX4-dependent factor X and by NKX1.2 protein.)

$$
\frac{\partial N K_{m}}{\partial t}=\alpha_{N K m}\left(\frac{\left(W / W_{W N K}\right)^{a}}{\left(1+\left(W / W_{W N K}\right)^{a}+\left(N K / N K_{N K N K}\right)^{r}+\left(X / X_{X N K}\right)^{r}\right)}\right)-\beta_{N K m} N K_{m}
$$

NKX1.2 protein: $N K(t)$

$$
\frac{d N K}{d t}=\alpha_{N K p} N K_{m}-\beta_{N K p} N K
$$

$C d x 4$ mRNA: $C_{m}(t)$

( $C d x 4$ is induced by FGF8 and WNT8C and inhibited by a PAX6-dependent factor Y.)

$$
\frac{\partial C_{m}}{\partial t}=\alpha_{C m}\left(\frac{\left(F / F_{F C}\right)^{a}+\left(W / W_{W C}\right)^{a}}{\left(1+\left(F / F_{F C}\right)^{a}+\left(W / W_{W C}\right)^{a}+\left(Y / Y_{Y C}\right)^{r}\right)}\right)-\beta_{C m} C_{m}
$$

CDX4 protein: $C(t)$

$$
\frac{\partial C}{\partial t}=\alpha_{C p} C_{m}-\beta_{C p} C
$$

Factor $X$ mRNA: $X_{m}(t)$ 
(Factor $X$ is induced CDX4. We have assumed that $X$ is inhibited by high FGF8 levels since repression of Nkx1.2 by CDX4-dependent Factor X is not effective in NMP zone.)

$$
\frac{\partial X_{m}}{\partial t}=\alpha_{X m}\left(\frac{\left(C / C_{C X}\right)^{a}}{\left(1+\left(C / C_{C X}\right)^{a}+\left(F / F_{F X}\right)^{r}\right)}\right)-\beta_{X m} X_{m}
$$

X protein: $X(t)$

$$
\frac{\partial X}{\partial t}=\alpha_{X p} X_{m}-\beta_{X p} X
$$

Pax6 mRNA: $P_{m}(t)$

(Pax6 is induced by CDX4 and RA working cooperatively, and is inhibited by NKX1.2)

$$
\frac{\partial P_{m}}{\partial t}=\alpha_{P m}\left(1+\frac{\left(C / C_{C P}\right)^{a}}{\left(1+\left(C / C_{C P}\right)^{a}+\left(N K / N K_{N K P}\right)^{r}\right)}\right)\left(\frac{\left(R / R_{R P}\right)^{a}}{\left(1+\left(R / R_{R P}\right)^{a}\right)}\right)-\beta_{P m} P_{m}
$$

PAX6 protein: $P(t)$

$$
\frac{\partial P}{\partial t}=\alpha_{P P} P_{m}-\beta_{P P} P
$$

Factor $Y$ mRNA: $Y_{m}(t)$

(Synthesis activated by PAX6, and inhibited by FGF8.)

$$
\frac{\partial Y_{m}}{\partial t}=\alpha_{X m}\left(\frac{\left(P / P_{P Y}\right)^{a}}{\left(1+\left(P / P_{P Y}\right)^{a}+\left(F / F_{F Y}\right)^{r}\right)}\right)-\beta_{Y m} Y_{m}
$$

Y protein: $Y(t)$

$$
\frac{\partial Y}{\partial t}=\alpha_{Y p} Y_{m}-\beta_{Y p} Y
$$

Ngn2 mRNA: $N_{m}(t)$

(Synthesis activated by PAX6 and inhibited by factor X.)

$$
\frac{\partial N_{m}}{\partial t}=\alpha_{N m}\left(\frac{\left(P / P_{P N}\right)^{a}}{\left(1+\left(P / P_{P N}\right)^{a}+\left(X / X_{X N}\right)^{r}\right)}\right)-\beta_{N m} N_{m}
$$

Name definition and values for the Hill constants used in the transcription factor network are found in Table 2. For all these transcription factors, the rate constants of mRNA and protein synthesis and degradation have not been determined experimentally. Hence, all the values are kept similar based on values used in published models [37, 38]. The only exception was CDX4, as CDX proteins are known to have increased stability [53].

Constant for mRNA synthesis/degradation: $\alpha_{i m}=1 / \min \beta_{i m}=0.03 / \mathrm{min}$

Constant for protein synthesis/degradation: $\alpha_{i p}=1 / \min \beta_{i p}=0.2 / \mathrm{min}$

CDX4 constant for protein synthesis/degradation: $\alpha_{C p}=1 / \min \beta_{C p}=0.05 / \mathrm{min}$

\section{Results}

\section{FGF-WNT-RA signaling interaction network can drive signaling switch}

In order to model the transcription factor network responsible for spinal cord cell maturation (Fig 1C), we first simulated the signaling dynamics between FGF, WNT and RA driving the system in the chick caudal neural tube $[16,27]$. Although several partially redundant FGF and WNT factors are transcribed within and around the caudal neural plate $[27,54]$, in chick, the 
Table 2. Hill constant for correct spatiotemporal distribution of cellular states.

\begin{tabular}{l|l|c}
\hline Hill constants & \multicolumn{1}{|c}{ Description } & Value* \\
\hline$F_{F T}$ & FGF8 dependent activation of $T$ & 10 \\
\hline$F_{F S}$ & FGF8 dependent activation of Sox2 & 50 \\
\hline$F_{F C}$ & FGF8 dependent activation of $C d x 4$ & 1 \\
\hline$F_{F X}$ & FGF8 dependent repression of $X$ & 1 \\
\hline$F_{F Y}$ & FGF8 dependent repression of $Y$ & 10 \\
\hline$W_{W N}$ & WNT8C dependent activation of $N k x 1.2$ & 10 \\
\hline$W_{W C}$ & WNT8C dependent activation of Cdx4 & 2 \\
\hline$S_{S T}$ & SOX2 dependent repression of $T$ & 20 \\
\hline$T_{T S}$ & T dependent repression of Sox2 & 100 \\
\hline$N_{N N}$ & NKX1.2 dependent repression of $N k x 1.2$ & 20 \\
\hline$N_{N P}$ & NKX1.2 dependent repression of Pax6 & 10 \\
\hline$C_{C X}$ & CDX4 dependent activation of $X$ & 10 \\
\hline$C_{C P}$ & CDX4-RA complex dependent activation of Pax6 & 1 \\
\hline$R_{R S}$ & RA dependent activation of Sox2 & 10 \\
\hline$R_{R P}$ & RA dependent activation of $P a x 6$ & 1 \\
\hline$X_{X N}$ & X dependent repression of $N k x 1.2$ & 1 \\
\hline$X_{X N 2}$ & X dependent repression of $N g n 2$ & 5 \\
\hline$P_{P Y}$ & PAX6 dependent activation of $Y$ & 20 \\
\hline$P_{P N 2}$ & PAX6 dependent activation of $N g n 2$ & 5 \\
\hline$Y_{Y C}$ & Y dependent repression of $C d x 4$ & \\
\hline & & \\
\hline
\end{tabular}

${ }^{*}$ Correct spatiotemporal distribution of cellular states was also obtained when individual values are increased or decreased by $30 \%$.

https://doi.org/10.1371/journal.pone.0244219.t002

most relevant factors are FGF8 and WNT8C [27]. Fgf8 is transcribed in the caudal stem zone (Fig 1A), where it activates $W n t 8 c$ transcription [27] and represses RA by inhibiting transcription of the RA synthesis enzyme Raldh2 and by activating transcription of the RA degradation enzyme Cyp26a [25]. FGF8 inhibition of RA production is circumvented rostrally by Fgf 8 mRNA decay [41] and by WNT8C, which stimulates RA production by outcompeting FGF8-mediated Raldh2 repression [27]. Once Raldh2 induction has occurred in nascent somites, its expression is maintained through unknown mechanisms, even in the absence of WNT activity [27]. For simplification, our model assumes that RA maintains Raldh2 transcription through positive autoregulation [55]. RA produced by somites then diffuses caudally and inhibit $F g f 8$ transcription $[25,56]$. These interactions give rise to an extended negative feedback loop between FGF and RA (Fig 2A).

At the stages examined, cell proliferation in the stem zone extend the vertebrate body axis caudally by producing the cells that, upon maturation, will give rise to the embryo's trunk [9]. To simulate the tissue's caudal ward movement, the signaling interactions were confined to a caudally moving spatial maturation domain of constant length extending rostrally from the stem cell zone to the anterior boundary of the most recently formed somite (Fig 2B; [28]). Thus, from the perspective of the caudal end, the moving spatial maturation domains appears stationary. To simulate the interactions between signaling factors, we used partial differential equations that integrated synthesis, degradation, and diffusion constant through interaction parameters or Hill constants. The Hill constant of a given reaction is defined as the concentration of a factor at which the rate of reaction regulated by the factor is half of the maximum possible rate. Hence, Hill constants are inversely related to the affinity of a factor for its target and can act as a measure of the factor's interaction strength (S1 Fig). 
To understand the possible behaviors that could originate from the extended FGF-WNT-RA network, we analyzed the system's output after systematically changing the signaling inputs and the strength of interaction between components (strong Hill constant $=0.1$ to weak Hill constant $=100$ ). By varying the interaction strength between FGF, WNT and RA components we obtained various temporal signaling information profiles that we grouped into four broad behaviors: FGF-dominance, FGF-RA balance, FGF-RA switch, and RA aberrant/oscillatory.

FGF8 dominance. In a system where FGF8 repression of Raldh2 transcription outweighs RA repression of $F g f 8$ transcription, the interactions do not result in appreciable RA production (e. g., Table 1-I; Fig 2C, S2A Fig). Such a system would lead to maintenance of pluripotent stem progenitor cells without differentiation.

FGF8-RA balance. FGF8, WNT8C and RA signaling domains balance each other and settle on a stable steady state profile (Table 1-II; Fig 2D, S2A and S2B Fig). Such steady state is achieved when the activating and repressive interactions of the system reach an equilibrium. In these conditions, the regions of FGF8 and RA activities are restricted to domains that maintain the same distance from one. This equilibrium could be broken at the onset of tail bud stages of development (18-21 somite stage) by the activation of signals that terminate axial elongation such as GDF11 [30, 31].

FGF-RA switch. One of the most interesting behavior obtained from the simulation is where the system starts with an Fgf8 mRNA gradient and ends with RA activity gradient over the entire spatial domain (Table 1-III; Fig 2E, S2A Fig). This behavior simulates a system that starts with a caudally located stem cell zone and a field of undifferentiated cells that is gradually converted, in a rostral to caudal direction, to a field of differentiate cells. Significantly, this differentiation process is one of the mechanism by which axial elongation is thought to cease in embryos $[18,57]$. The rate at which the FGF8-to-RA transition occurs, and hence differentiation, is modulated by the strength of mutually repressive FGF-RA interactions (Table 1-IV through VI; Fig 3). Factors that change FGF activity levels (e.g., GDF11; [30, 31]) could effectively changing the strength of repressive interactions between FGF and RA and, therefore, the timing of axial growth termination.

RA aberrant/oscillatory. Some parameters in the FGF-WNT-RA interaction system lead to an oscillation in RA levels that did not match the behavior of the system in vivo. These oscillations occurred when Hill constants for RA inputs were weak, particularly for the RA-dependent autoregulation of Raldh2 production (Table 1-VII, VIII; S3 Fig). In some cases, the system produced a discrete burst of RA at the position where the FGF-RA switch was observed, to then return to produce FGF (Table 1-VII; S3A Fig). In other cases, the burst of RA separated the caudal area of FGF production from a rostral area where FGF and RA production alternated in an oscillatory manner (Table 1-VIII; S3B Fig).

Altogether, our results show that the FGF8-WNT8C-RA interaction network postulated by Olivera-Martinez and colleagues [27] can indeed give rise to a signaling switch that travels caudally during the elongation of the embryonic axis. The model also leaves open the possibility for additional factors to terminate axial elongation (e.g., GDF11; [30, 31]). The behavior of the switch depends on several interaction parameters that, in coordination, regulate the position and size of the region of cell differentiation.

\section{FGF-WNT-RA signaling switch and transcription factor network establish areas of pluripotency, early and late differentiation}

To simulate the dynamics of the transcription factor network, we integrated the transcription (Fig 1C) and signaling (Fig 2A) networks into a single supra-network (Fig 4A). We then used 
A

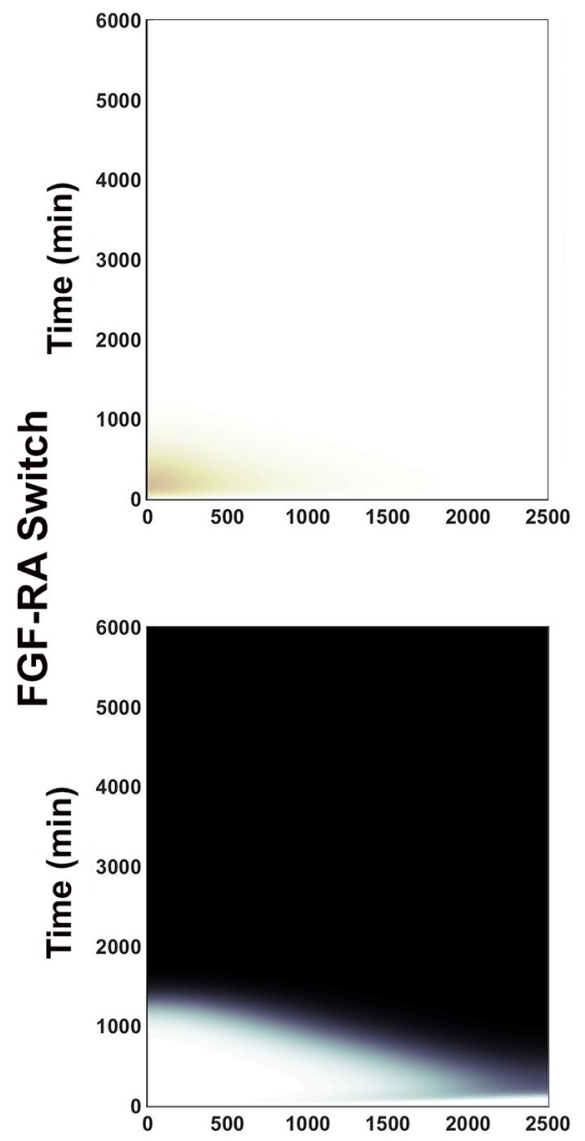

B
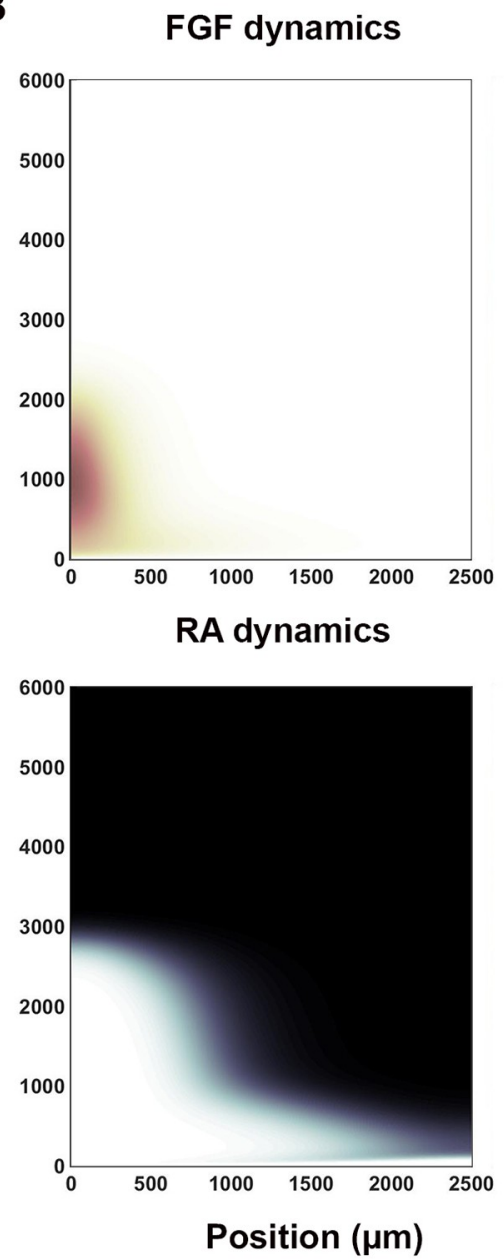

C
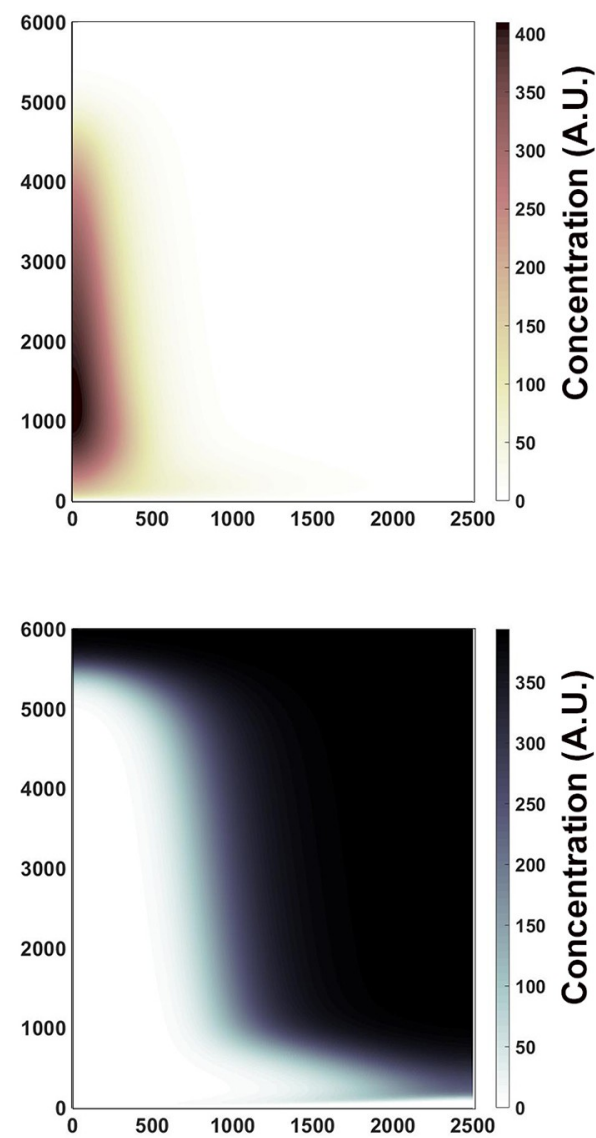

Fig 3. RA inputs strength determine FGF-RA switch rate of conversion. The strength by which WNT8C stimulates ( $\left.\mathrm{W}_{\mathrm{WR}}\right)$ and FGF8 represses $\left(\mathrm{R}_{\mathrm{RF}}\right) \mathrm{Raldh}_{2}$ transcription determines RA's spatial profile over time ( $\mathrm{x}$ and $\mathrm{y}$ axes, respectively). (A) Fast FGF-RA switch ( $\mathrm{t}<1500$ min) results from relatively moderate activation and very strong repression inputs $\left(\mathrm{W}_{\mathrm{WR}}=0.5, \mathrm{R}_{\mathrm{RF}}=0.1\right)$. (B) Intermediate FGF-RA switch $(\mathrm{t}<3000 \mathrm{~min})$ results from relatively strong activation and moderate repression inputs ( $\mathrm{W}_{\mathrm{WR}}=0.2, \mathrm{R}_{\mathrm{RF}}=0.3$ ). (C) Slow FGF-RA switch $\left(\mathrm{t}<5500 \mathrm{~min}\right.$ ) results from moderate activation and repression inputs ( $\mathrm{W}_{\mathrm{WR}}$ $\left.=0.5, R_{R F}=0.45\right)$. FGF and RA heat map scale is shown on the right (arbitrary units; A. U.).

https://doi.org/10.1371/journal.pone.0244219.g003

the FGF-RA balance profile output as the input for the system (Figs 2D and 4B), as it most closely resembles the distribution of signaling activity and NP cell behaviors during the steady state period of embryo growth (10-18 somite stage; Fig 1A). In this simulation, we followed the transcriptional profile of cells as they are born caudally at $t=0$ and at subsequent times are displaced rostrally by the appearance of new cells. During their rostral displacement, cells move away from the stem cell zone and the source of FGF and WNT production (Fig 4C). As FGF/WNT level decrease, RA levels increase following the FGF-RA balance profile simulation (Figs $2 \mathrm{D}$ and $4 \mathrm{~B}$ ). These changes in spatial signal information are the drivers for transcription factor expression. Since the cells are arranged spatially from caudal to rostral in order of birth, the temporal changes in transcription factors give rise to spatial changes in profiles.

The transcription output of the system depends on signaling inputs and transcription factor interactions. Signals regulate the transcription factor network at two distinct key points. The first point of regulation is towards the caudal end of the chick embryo, where FGF8 and WNT8C, alone or in combination, are required for T (Bra), Sox2, Nkx1.2 and Cdx4 
A

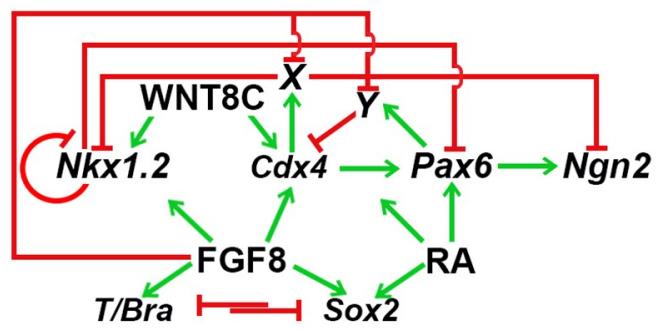

B

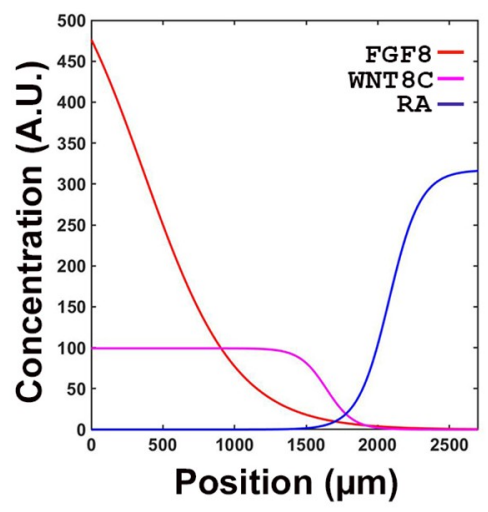

C

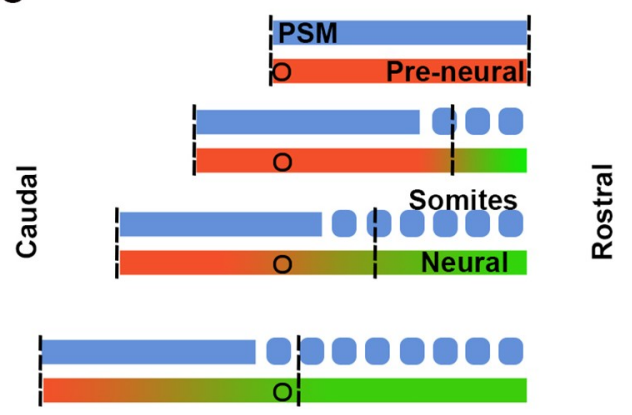

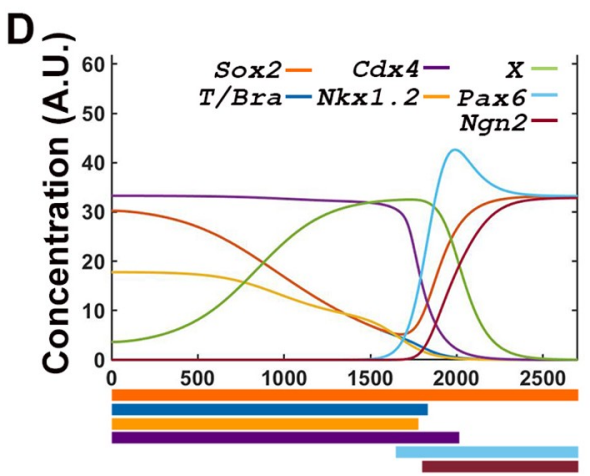

E

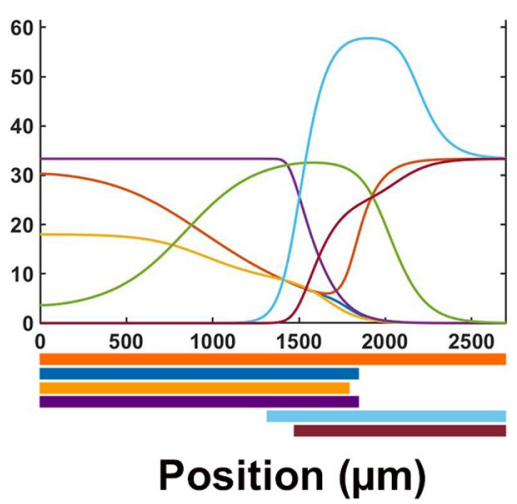

$\mathbf{F}$

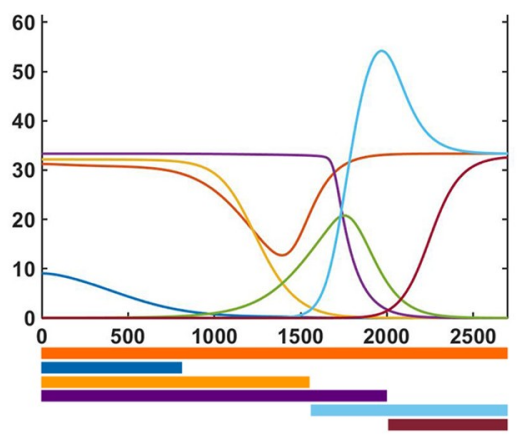

Fig 4. Strength of interactions between transcription factors determine the response of the network to signal information. (A) Integrated transcription and signaling interaction network, including hypothetical factors X and Y, predicted from experimental data from reference [15]. (B) Reference FGF-RA switch input used for simulations (from Fig 2D). (C) Location of reference cell (circle) within the spatial maturation domain of signaling activity (vertical dashed lines). Cell remains in the location where it was born as the spatial maturation domain is displaced caudally (as in Fig 2B). (D-F) Transcription profile of cell with all interactions equally moderate (D; Hill constants $=20$ ), equally strong ( $\mathrm{E}$; Hill constants $=2$ ), and variable (F; as defined in Table 2). Output of simulation in F most closely resembles the staggered distribution of transcription factors observed in embryos (Fig 1B; [15]). Colored bars at the bottom of each graph represent the spatial domain of gene transcription: Sox2 in dark orange; T/Bra in dark blue; Nkx1.2 in light orange; $C d x 4$ in purple; Pax6 in light blue; and Ngn2 in maroon.

https://doi.org/10.1371/journal.pone.0244219.g004

transcription [17, 58-60]. Independently of signaling inputs, $N k x 1.2$ transcription is negatively regulated by CDX4 and its own protein product $[15,61]$. The second point of regulation is towards the rostral end of the neural plate, where RA cooperates with CDX4 to activate the early differentiation gene Pax6 [15, 62]. Pax6 is also negatively regulated by NKX1.2 [15, 63]. In contrast, transcription of late differentiation gene Ngn2 is activated by PAX6 and repressed by CDX4 $[15,26]$. Given that CDX4 is an activator [64], our model invokes two putative CDX4-regulated transcriptional repressors $X$ and $Y$ to indirectly repress Nkx1.2 and Ngn2 [15]. These hypothetical repressors are assumed to be inhibited by FGF8 [15].

Together, the signal and transcription factor network were able to generate correct gene transcription profile in many but not all instances (Fig 4D-4F), indicating that only under certain parameter restrictions could the network recapitulates embryonic events. In principle, the spatial dynamics of the signal interactions network should be sufficient to activate transcription factor network components in the correct spatiotemporal sequence: high FGF caudally would promote pluripotency while high RA rostrally would promote differentiation, with cross-repressive interaction between pathways maintaining the domains separate at opposite ends of the tissue. However, if all the interactions in the network are equally moderate (Hill constants $=20$, Fig $4 \mathrm{D}$ ) or equally strong (Hill constants $=2$, Fig $4 \mathrm{E}$ ), then the network does 
not result in the proper spatial resolution of temporal states. In both cases, transcription of the mesoderm marker $\mathrm{T} / \mathrm{Bra}$ is not restricted to the caudal end, but instead, it is detected throughout the caudal two thirds of the tissue, partially overlapping with Pax6 and Ngn2 gene transcripts (Fig 4D, 4E). Only a subset of interaction strengths give rise to correct spatial order of identities (Table 2; Fig 4F). The values of the interactions strengths that generate proper spatial distribution of transcripts could be increased or decreased by $30 \%$. These values define a parametric space where the model is operational and highlights its robustness (S4 Fig). These results suggest that signaling inputs encodes the information required for specifying different cell maturation states, but that it is the transcription factor network what determines the spatial distribution and organization of maturation states cell along the caudal-to-rostral length of the tissue.

\section{The transcription network executes the spatiotemporal information provided by the signaling factor network}

To further evaluate the contribution of signaling and transcription factors networks on cell maturation events, we tested the effect of disrupting individual network nodes on transcription readouts. First, we tested the response of the transcription network to signaling noise. In simulations, both periodic disturbance (Fig 5A) and random noise (Fig 5B) were well tolerated by the transcription network without any distortions in the spatiotemporal resolution of the cellular states. Unexpectedly, introduction of random noise resulted in better separation of early

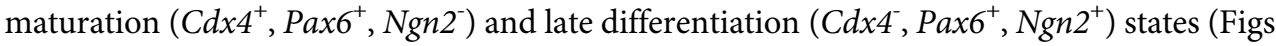
$4 \mathrm{~F}, 5 \mathrm{~B})$. This phenomenon, the system's ability to withstand perturbations by retaining NP cells in developmental trajectories, suggests that canalization is an emerging property of the signal-transcription factor supra network.

Next, we evaluated the role of signaling gradients in determining the spatiotemporal resolution of downstream targets' transcriptional domains. Replacing the exponential gradient of the signaling factors with a Boolean switch (Fig 5C) or a linear gradients (Fig 5D), resulted in loss of proper resolution of transition zones. Thus, changes in the spatial information contained in the signaling network changes the transcription network readouts. This confirms that the spatial information is encoded in the signal and not in the transcription factor network.

We previously proposed a central role of CDX4 in regulating maturation of NPs in the chick pre-neural tube. To theoretically test CDX4 role in transcription network regulation, we removed, increased or introduced noise to $C d x 4$ transcription and evaluated the network's transcription profile output (Fig 6). When $C d x 4$ was removed from the simulation, $N k \times 1.2$ transcription expanded rostrally, overlapping significantly with the expression of differentiation markers Pax6 and Ngn2 (Fig 6A). This phenomenon is opposite to what is observed experimentally, were downregulation of CDX4 activity using an ENRCDX4 repression construct results in downregulation of Nkx1.2 [15] (discussed below). Conversely, when the levels of $C d x 4$ were increased in the simulation, $N k x 1.2$ expression domain shifted caudally and away from Pax6 expression domain, and rostral cells did not activate the late differentiation gene Ngn2 (Fig 6B), in agreement with experimental results [15]. Thus, removing or increasing $C d x 4$ transcription affects the spatial relationship between early specification gene Nkx1.2 and neural differentiation gene Ngn2. This result suggests that CDX4 functions in the network to establish a transition zone between pluripotency and differentiation states. CDX4 function is robust and integral to the canalization properties of the system, as introduction of transcriptional noise produces the expected gene expression profile with only minute changes in the position of boundary transitions ( $<+/-30 \mu \mathrm{m}$; Fig $6 \mathrm{C})$. Excluding the effect of removing CDX4 on Nkx1.2 (discussed below), our simulations agrees with in vivo observations [15], and support a role of CDX4 in driving NP maturation during early spinal cord development. 
A

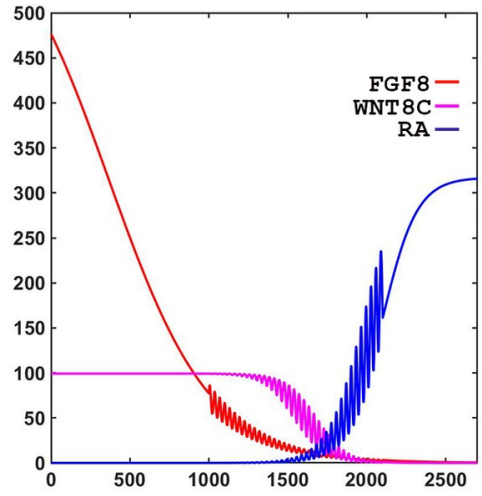

B

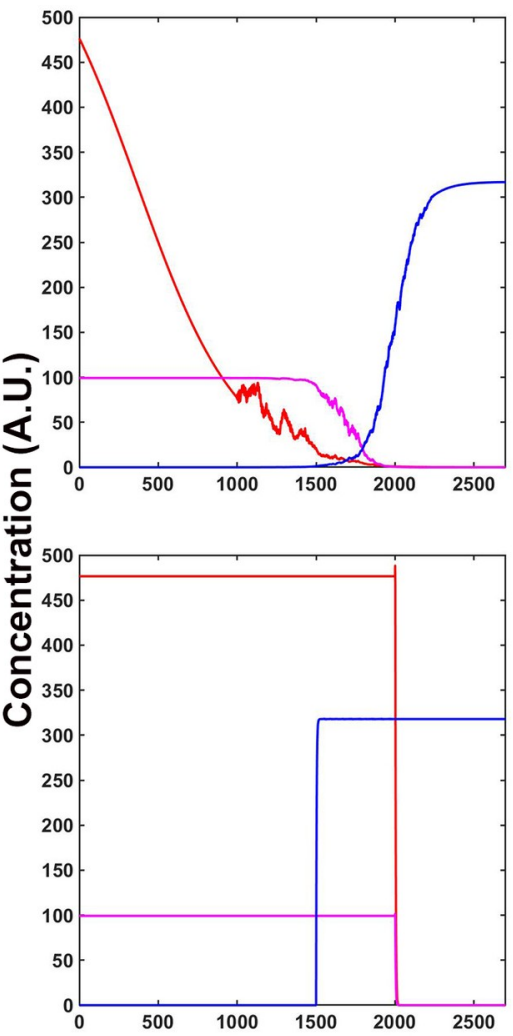

D

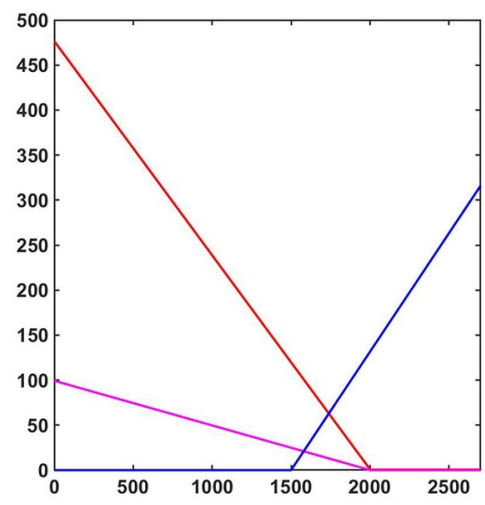

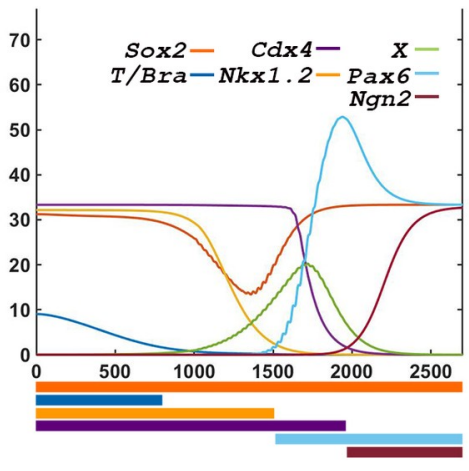
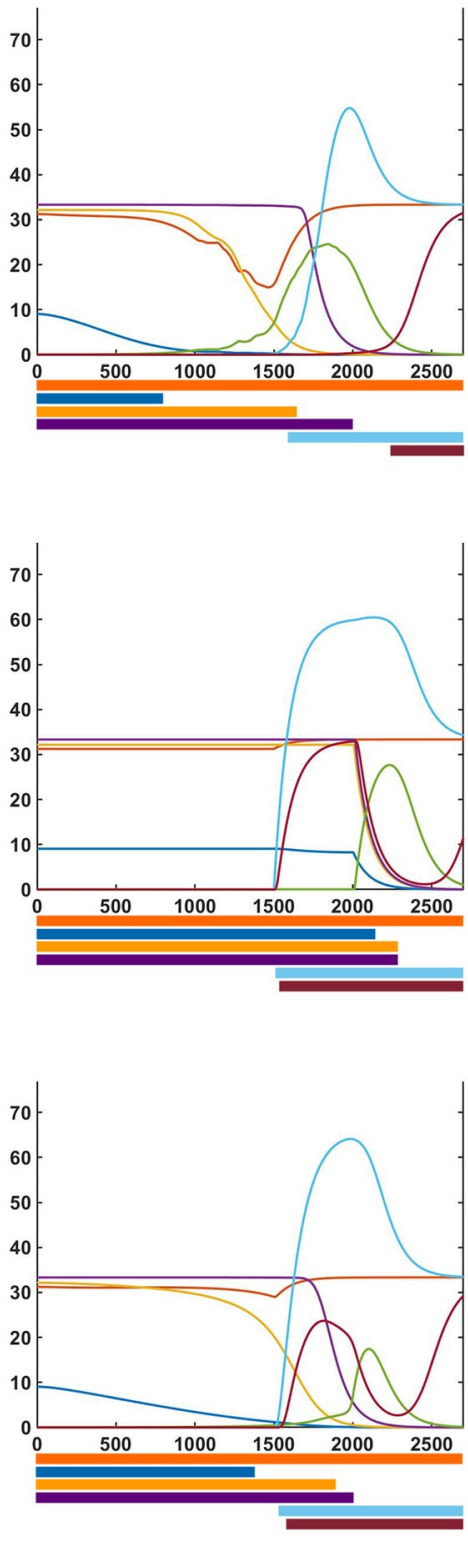

Position ( $\mu \mathrm{m})$ 
Fig 5. Transcription factor network is resilient to small and moderate alterations in signaling information. (A, B) Transcription factor output is not affected by oscillatory (A) or random noise (B) in signaling inputs, as outputs are comparable to those obtained in conditions without noise (Fig 4F). (C, D) Large changes in signaling input such as discreet Boolean (C) and linear gradient (D) changes transcription factor expression domains.

https://doi.org/10.1371/journal.pone.0244219.g005

\section{Discussion}

\section{Signaling factor simulation recapitulates signaling dynamics observed in natural systems}

Our simulations describe the possible behaviors the FGF8-WNT8C-RA system can exhibit under various interaction conditions (Fig 2). With small variations in interactions' strength, the system can model behaviors associated with different stages of axial tissue development. In a system where the FGF's activity dominates over RA's activity, the simulation most closely resembles the neural tissue at early stages of axial extension (in chick, before 6 somite stages), whereas in a system where FGF activity balances that of RA, the simulation resembles the maturation of spinal cord cell that occurs during axial elongation before the formation of the tail bud (in chick, 6-18 somite stages). In contrast, a switch in the system from FGF to RA most closely resembles the processes occurring during termination of body axis extension [10, 28], with or without the aid of additional factors (e.g., GDF11; [30, 31]). Significantly, when the interactions between FGF and RA components are weak, the system oscillates, resembling the oscillations observed between FGF/WNT and the NOTCH signaling pathway during the process of paraxial mesoderm segmentation [65]. Thus, with small modifications in signal components interaction, one can observe large changes in the behavior of the system equivalent to the changes normally observed in the tissues emerging from the caudal lateral epiblast during axial elongation, the paraxial mesoderm and spinal cord.

We propose a model of vertebrate body extension where modulation of interaction strength between different components of the system (e.g., transcriptionally, post-transcriptionally or epigenetically), could regulate the spatiotemporal dynamics involved in vertebrate body extension. In this model, the time at which the system transitions from FGF dominant, to FGF-RA balance, to RA switch respectively determine the time of tissue induction, elongation and termination. For example, a long period in which the FGF8-RA balance system is operational could explain the elongated axis of vertebrates such as snakes; as long as the FGF8-RA balance system remains operational, the caudal progenitor/stem cell pool will continue to generate tissue and extend the axis. In this scenario, the time at which RA takes over the system to initiate progenitor cell differentiation will determine the axial body length. This last process can be accelerated by other factors that dampen FGF and Wnt signaling activity such as GDF11 [30, 31]. A second mechanism for terminating axial elongation is the activation of Hox 13 genes [66], whose activation in mouse is under the control of CDX factors as well as GDF11 [31, 66].

\section{Transcription network simulations recapitulate the cell state transitions observed in the caudal neural plate}

Results from simulations support a role for CDX in coordinating upstream signaling factors with downstream transcription network components involved in spinal cord neural maturation. In the present model, CDX4 functions to separate caudal stem cell populations (Nkx1.2

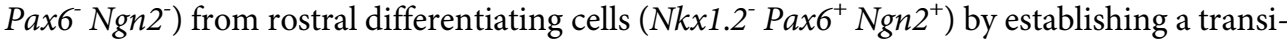
tion zone. This is achieved by CDX4 repressing the bipotency gene Nkx1.2 and the late differentiation gene Ngn2, and by activating the early differentiation gene Pax6. In simulations, high levels of $C d x 4$ transcription resulted in downregulation of CDX4 repressed genes (Fig 6B): 
A

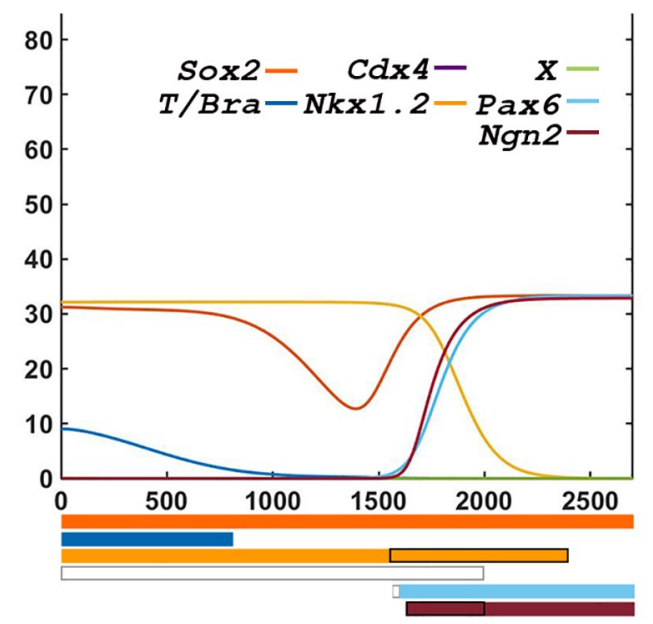

B

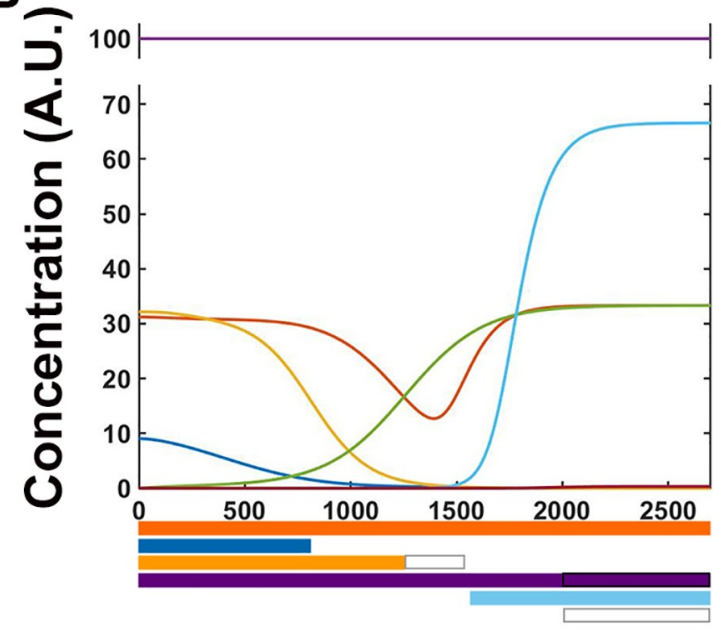

C

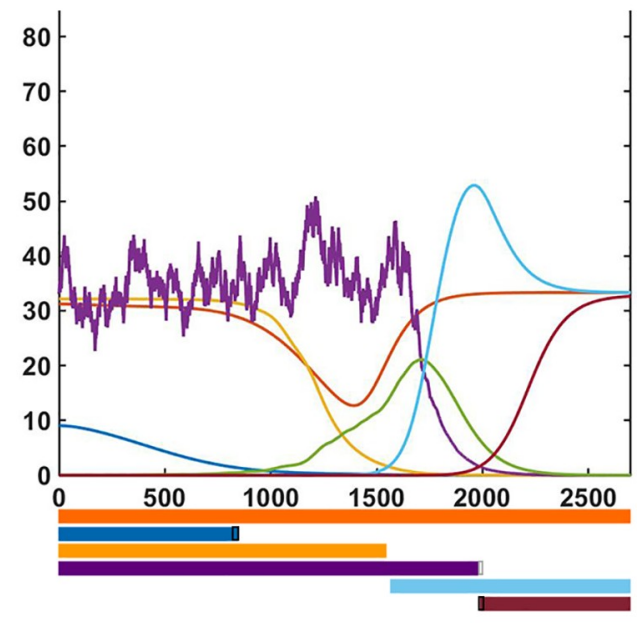

Position ( $\mu \mathrm{m})$ 
Fig 6. CDX4 is necessary for proper interpretation of signaling inputs by the transcription factor network. (A) Compared to control simulation (Fig $4 \mathrm{~F}$ ), loss of $C d x 4$ expression causes a large rostral expansion of $N k x 1.2$ domain, a small reduction in Pax6 domain and a large caudal expansion in Ngn2 domain. These changes results in the overlap of stem and differentiation gene expression domains. (B) Overexpression of Cdx4 reduces Nkx1.2 and eliminates Ngn2 expression domains, effectively expanding the early and eliminating the late differentiation zones. (C) Introduction of random noise in $C d x 4$ transcriptional noise has insignificant effects on the system's spatial expression profiles. In the expression profile bars at the bottom of the graphs, white and black rectangles indicate loss and gain of gene transcription, respectively.

https://doi.org/10.1371/journal.pone.0244219.g006

Nkx1.2 transcription domain shifted caudally and Ngn2 transcription was lost. In these conditions, only the caudal expression of $N k x 1.2$ was retained due to its high dependence on WNT stimulation [61]. Increasing $C d x 4$ transcription did not affect the expression domain of Pax6, as transcription of this gene is also dependent on RA secreted from somites [15, 62]. Together, the changes in Nkx1.2 and Ngn2 transcription induced by CDX4 overexpression effectively increase the size of the transition zone. The same way that premature activation of differentiation signals has been predicted to cause shortening of the embryonic axis [18], a greater separation of stem cell and differentiation signals is predicted to cause axial lengthening. These predictions would need to be tested experimentally.

Significantly, results obtained by simulating loss of $C d x 4$ activity (Fig 6A) did not fully match experiments done in vivo. With respect to differentiation genes, the network recapitulates the in vivo results: Pax6 transcription was not affected due to dependence of this gene on RA [15, 62], whereas Ngn2 transcription was upregulated because this gene is normally repressed by CDX4 [15]. In contrast, with respect to the NMP marker Nkx1.2, loss of Cdx4 caused an anterior expansion of Nkx1.2 expression domain that was not observed experimentally. This discrepancy can be attributed to the use of a dominant negative form of CDX4 instead to knockout allele to downregulate the activity of this gene in vivo (ENRCDX4; [15]). Dominant-negative ENRCDX4 works by outcompeting endogenous CDX4 from binding to its target genes and repressing their transcription [67]. This approach is different than not having CDX4 protein altogether (e. g, through deletion of the gene). Given that our model simulates the loss of CDX4 function and not the active repression of its downstream target genes, this providing a possible explanation for the observed discrepancies between experimental systems. It is also possible that our current understanding of the transcription factor network is incomplete. For example, NOTCH signaling pathway is involved in NP cell proliferation [32, 33], but was omitted from our system due to lack of information related to its interaction with $C d x 4$ and Nkx1.2. It is possible, however, that NOTCH is a positive regulator of $N k x 1.2$ in a manner similar to its regulation of $N k x 6.1$, a close family member involved in ventral spinal cord cell specification [68]. These two possible explanations are not mutually exclusive, and could be resolved with additional experiments. While additional experiments will be required to fully understand CDX4 function in the NMP zone, even with its limitations, the proposed transcription factor network supports a key role for CDX4 in the segregation of cell states in the nascent spinal cord.

Noise is an intrinsic property of biological systems [69]. To explain the resilience of developmental systems to genetic or environmental noise and perturbations, Waddington introduced the concept of canalization [8]. In our simulation, the introduction of random noise produced a more accurate representation of the cell maturation states observed in vivo than those produced without any type of noise (e.g., separation of late maturation and differentiation states; Figs 4F, 5B). In addition, deviation of up to $30 \%$ in the system's parametric values (Table 2) did not change the spatial distribution of cell maturation states. This exceptional robustness was an unexpected emerging property of the system that was not obvious from experimental data [15]. We propose that the network's resiliency to intrinsic (random noise) 
and extrinsic (artificial variation in parameters) variations could function to canalize NPs to their mature state, and that the source of the system's canalization capacity is the network's organization itself [70].

\section{Future perspectives}

The findings uncovered in our chick embryo model are generalizable to other vertebrates, despite embryonic differences in tissue size, geometry and heterochrony. In all species examined so far, similar but not identical signal and transcription factors control spinal cord cell specification and maturation $[9,10,25,71]$. Similar to chick, mouse and zebrafish NMP bipotent state is driven by FGF/WNT pathways regulating T/Bra and Sox 2 transcription, with differences residing in the specific FGF or WNT regulating each pathway [19-21, 71, 72]. For example, WNT8c in chick and WNT3a in mouse control axial elongation and NMP cell fate decisions (reviewed in [10]). Different WNT proteins are post-translationally modified in a number of ways, and these variations can change their extracellular transport and diffusion (reviewed in [73]), which would directly affect the shape of their gradient. While this idea need to be tested experimentally, it is possible that differences in individual network components help adapting an otherwise conserved network to tissues with different morphologies and rates of development.

Although the integrated signaling and transcription factor network model presented here provides key information on the transition state drivers underlying neuronal cell maturation, it is clear from experimental and modelling data that the model is far from complete. For example, several signaling and transcription factors were omitted from the system due to either lack of information regarding their interactions with other network members (e.g., $\mathrm{NOTCH} ;[32,33]$ ), or reports that those factors are not operational during the developmental stages that the system analyses (chick 10-18 somite stage; e.g., other CDX family members, [29]; GDF11, [30, 31]; Hox13 genes, [31, 66]). Another missing component are the feedback controls that transcription factors have over the signaling network. In mouse, chromatin immunoprecipitation studies using epiblast stem cells derived from wild type or CDX2-deficient primitive streaks have shown that CDX transcription factors can regulate several WNT and FGF pathway components (Wnt5a, Rspo3, Fgf4 and Fgf8; [74]), indicating feedback regulation between transcription and signaling networks. Similarly, CDX binding sites present in Radh2 intronic enhancer are sufficient to drive reporter gene expression in the caudal end of embryos [75]. Currently, however, lack of quantitative data precluded the incorporation of feedback activities into an integrated network model.

Our modeling results also highlights the importance of signaling factor regulation by components external to the signaling pathways. For example, our model shows that maintenance of RA production is critical for the behavior of the system, as weakening of the Hill constant regulating RA-dependent autoregulation of Raldh2 production causes the system to transition from balanced to oscillatory (Table 1-VII, 1-VIII; S3 Fig). While, for simplification purposes we assumed that Raldh2 maintenance is dependent on RA, it is likely to be dependent on transcription factors, some of which are part of our transcription network (e.g. CDX; [75]). Understanding the effect that transcription factor network components have over the signaling network will be important for understanding the later stages in neural cell maturation and their subsequent differentiation.

\section{Supporting information}

\section{S1 File.}

(DOCX) 
S1 Fig. Hill constant determine the strength of response of targets to activators and repressors. Temporal response of targets with different Hill constants to activators and repressors. Inputs are shown in blue and targets with different Hill constants are color coded: $\mathrm{H1}=1$, orange; $\mathrm{H} 2=10$, yellow; $\mathrm{H} 3=20$, purple; and $\mathrm{H} 4=100$, green. (A-B) For activators, constant (A) and graded (B) inputs induce targets with smaller Hill constants to higher levels than targets with larger Hill constants. (C-D) For repressors, constant (C) and graded (D) inputs reduce targets with smaller Hill constants to lower levels than targets with larger Hill constants. With graded inputs (B, D), larger Hill constants also cause temporal delays in response. (TIF)

S2 Fig. Changes in FGF-WNT-RA signaling interactions results in mRNA profiles parallel protein accumulation and are stable over time. (A) Profiles of mRNA transcripts at $t=6000$ min associated with production of signaling molecules. Transcript and protein profiles are similar (Fig 2C left panels). (B) Signaling molecule profiles are stable over longer simulation times. An FGF-RA balance simulation that was run for $\mathrm{t}=30,000$ min produced the same profile than a simulation that was run for $\mathrm{t}=6000 \mathrm{~min}$ (Fig 2C middle row).

(TIF)

S3 Fig. RA positive autoregulation is required for bistability. Reducing RA's positive effect on Raldh2 transcription ( $\mathrm{H}=300$ instead of 50) results in aberrant RA, but not FGF, distribution. (A) Under these conditions, when FGF affinity to repress Raldh2 is strong ( $\mathrm{H}=2$ instead of 10), a peak of RA production forms at a position in the field where the FGF-RA switch would have occurred $(1500-2000 \mu \mathrm{m})$. (B) When RA repression of $F g f 8$ transcription is weakened $(H=20$ instead of 1$)$, RA production oscillates in the region of cell differentiation $(>1500 \mu \mathrm{m})$.

S4 Fig. Stability of the transcription profile in the parameter space. Changes in the strength of interactions between transcriptional factors does not drastically affect the transcriptional domain profile. (A) Original transcription profile as shown in Fig 4F. (B, C) Reducing (B) or increasing (C) all the Hill constants in the interaction network by $30 \%$ does not significantly change the spatial profile of gene transcription.

S1 Appendix. SIGNET.m: MATLAB code for simulating signaling dynamics. (M)

S2 Appendix. TRANSNET.m: MATLAB code for simulating transcriptional factor dynamics.

(M)

\section{Acknowledgments}

We thank Dr. Donald DeAngelis for guidance and for sharing his mathematical expertise, and members of the Skromne lab for intellectual discussion. We also thank Dr. K. G. Story (U Dundee, UK), Dr. M. Gouldin (Salk Institute, USA). Dr. F. Medeville (CBI, France), Dr. S. Mackem (NCI, USA), Dr. Y. Marikawa (U Hawaii, USA), Dr. A. V. Morales (Cajal Institute, Spain) and Dr. B. Novitch (UCLA, USA) for generously providing plasmids.

\section{Author Contributions}

Conceptualization: Piyush Joshi, Isaac Skromne. 
Data curation: Piyush Joshi.

Formal analysis: Piyush Joshi, Isaac Skromne.

Funding acquisition: Isaac Skromne.

Investigation: Piyush Joshi, Isaac Skromne.

Methodology: Piyush Joshi.

Software: Piyush Joshi.

Supervision: Isaac Skromne.

Validation: Piyush Joshi, Isaac Skromne.

Visualization: Piyush Joshi.

Writing - original draft: Piyush Joshi.

Writing - review \& editing: Piyush Joshi, Isaac Skromne.

\section{References}

1. Housden BE, Perrimon N. Spatial and temporal organization of signaling pathways. Trends Biochem. Sci. 2014; 39: 457-464. https://doi.org/10.1016/j.tibs.2014.07.008 PMID: 25155749

2. Egli D, Birkhoff G, Eggan K. Mediators of reprogramming: transcription factors and transitions through mitosis. Nat. Rev. Mol. Cell Biol. 2008; 9: 505-516. https://doi.org/10.1038/nrm2439 PMID: 18568039

3. Basson MA. Signaling in cell differentiation and morphogenesis. CSH Persp. Biol. 2012; 4: a008151. https://doi.org/10.1101/cshperspect.a008151 PMID: 22570373

4. Perrimon N, Pitsouli C, Shilo BZ. Signaling mechanisms controlling cell fate and embryonic patterning CSH Persp. Biol. 2012; 4: a005975. https://doi.org/10.1101/cshperspect.a005975 PMID: 22855721

5. Zaret KS, Watts J, Xu J, Wandzioch E, Smale ST, Sekiya T. Pioneer factors, genetic competence, and inductive signaling: programming liver and pancreas progenitors from the endoderm. CSH Symp. Quant. Biol. 2008; 73: 119-126.

6. Zaret KS, Carroll JS. Pioneer transcription factors: establishing competence for gene expression. Genes \& development. 2011; 25: 2227-2241. https://doi.org/10.1101/gad.176826.111 PMID: 22056668

7. Halfon MS, Carmena A, Gisselbrecht S, Sackerson CM, Jimenez F, Baylies MK, et al. Ras pathway specificity is determined by the integration of multiple signal-activated and tissue-restricted transcription factors. Cell. 2000; 103: 63-74. https://doi.org/10.1016/s0092-8674(00)00105-7 PMID: 11051548

8. Waddington $\mathrm{CH}$. Canalization of development and the inheritance of acquired characters. Nature. 1942; 150: 563-565.

9. Henrique D, Abranches E, Verrier L, Storey KG. Neuromesodermal progenitors and the making of the spinal cord. Development. 2015; 142: 2864-2875. https://doi.org/10.1242/dev.119768 PMID: 26329597

10. Wilson V, Olivera-Martinez I, Storey KG. Stem cells, signals and vertebrate body axis extension. Development. 2009; 136: 1591-1604. https://doi.org/10.1242/dev.021246 PMID: 19395637

11. Gouti M, Metzis V, Briscoe J. The route to spinal cord cell types: a tale of signals and switches. Trends Genetics. 2015; 31: 282-289. https://doi.org/10.1016/j.tig.2015.03.001 PMID: 25823696

12. Catala M, Teillet MA, Le Douarin NM. Organization and development of the tail bud analyzed with the quail-chick chimaera system. Mech Dev. 1995; 51: 51-65. https://doi.org/10.1016/0925-4773(95) 00350-a PMID: 7669693

13. Schoenwolf GC. Observations on closure of the neuropores in the chick embryo. Am J Anat. 1979; 155:445-465. https://doi.org/10.1002/aja.1001550404 PMID: 484511

14. Gouti M, Tsakiridis A, Wymeersch FJ, Huang Y, Kleinjung J, Wilson V, et al. In vitro generation of neuromesodermal progenitors reveals distinct roles for wnt signalling in the specification of spinal cord and paraxial mesoderm identity. PLoS Biology. 2014; 12(8): e1001937. https://doi.org/10.1371/journal.pbio. 1001937 PMID: 25157815

15. Joshi P, Darr AJ, Skromne I. CDX4 regulates the progression of neural maturation in the spinal cord Dev. Biol. 2019; 449: 132-142. https://doi.org/10.1016/j.ydbio.2019.02.014 PMID: 30825428 
16. Diez del Corral R, Olivera-Martinez I, Goriely A, Gale E, Maden M, Storey K. Opposing FGF and retinoid pathways control ventral neural pattern, neuronal differentiation, and segmentation during body axis extension. Neuron. 2003; 40: 65-79. https://doi.org/10.1016/s0896-6273(03)00565-8 PMID: 14527434

17. Delfino-Machin M, Lunn JS, Breitkreuz DN, Akai J, Storey KG. Specification and maintenance of the spinal cord stem zone. Development. 2005; 132:4273-4283. https://doi.org/10.1242/dev.02009 PMID: 16141226

18. Olivera-Martinez I, Harada H, Halley PA, Storey KG. Loss of FGF-dependent mesoderm identity and rise of endogenous retinoid signalling determine cessation of body axis elongation. PLoS Biology. 2012; 10: e1001415. https://doi.org/10.1371/journal.pbio.1001415 PMID: 23118616

19. Kawachi T, Shimokita E, Kudo R, Tadokoro R, Takahashi Y. Neural-fated self-renewing cells regulated by Sox2 during secondary neurulation in chicken tail bud. Dev. Biol. 2020; 461:160-171. https://doi.org/ 10.1016/j.ydbio.2020.02.007 PMID: 32059837

20. Koch F, Scholze M, Wittler L, Schifferl D, Sudheer S, Grote P, et al. Antagonistic Activities of Sox2 and Brachyury Control the Fate Choice of Neuro-Mesodermal Progenitors. Dev. Cell. 2017; 42: 514-526. https://doi.org/10.1016/j.devcel.2017.07.021 PMID: 28826820

21. Takemoto T, Uchikawa M, Yoshida M, Bell DM, Lovell-Badge R, Papaioannou VE, et al. Tbx6-dependent Sox2 regulation determines neural or mesodermal fate in axial stem cells. Nature. $2011 ; 470: 394$ 398. https://doi.org/10.1038/nature09729 PMID: 21331042

22. Yamaguchi TP, Takada S, Yoshikawa Y, Wu N, McMahon AP. T (Brachyury) is a direct target of Wnt3a during paraxial mesoderm specification. Genes Dev. 1999; 13: 3185-3190. https://doi.org/10.1101/ gad.13.24.3185 PMID: 10617567

23. Herrmann BG, Labeit S, Poustka A, King TR, Lehrach $\mathrm{H}$. Cloning of the T gene required in mesoderm formation in the mouse. Nature. 1990; 343: 617-622. https://doi.org/10.1038/343617a0 PMID: 2154694

24. Pituello F, Medevielle F, Foulquier F, Duprat AM. Activation of Pax6 depends on somitogenesis in the chick embryo cervical spinal cord. Development. 1999; 126: 587-596. PMID: 9876187

25. Diez del Corral R, Storey KG. Opposing FGF and retinoid pathways: a signalling switch that controls differentiation and patterning onset in the extending vertebrate body axis. BioEssays. 2004; 26: 857-869. https://doi.org/10.1002/bies.20080 PMID: 15273988

26. Bel-Vialar S, Medevielle F, Pituello F. The on/off of Pax6 controls the tempo of neuronal differentiation in the developing spinal cord. Dev. Bio. 2007; 305: 659-673. https://doi.org/10.1016/j.ydbio.2007.02. 012 PMID: 17399698

27. Olivera-Martinez I, Storey KG. Wnt signals provide a timing mechanism for the FGF-retinoid differentiation switch during vertebrate body axis extension. Development. 2007; 134:2125-2135. https://doi.org/ 10.1242/dev.000216 PMID: 17507413

28. Denans $\mathrm{N}$, limura $\mathrm{T}$, Pourquie $\mathrm{O}$. Hox genes control vertebrate body elongation by collinear Wnt repression. eLife. 2015; 4: 04379. https://doi.org/10.7554/eLife.04379 PMID: 25719209

29. Marom K, Shapira E, Fainsod A. The chicken caudal genes establish an anterior-posterior gradient by partially overlapping temporal and spatial patterns of expression. Mech. Dev. 1997; 64: 41-52. https:// doi.org/10.1016/s0925-4773(97)00043-9 PMID: 9232595

30. Jurberg AD, Aires R, Varela-Lasheras I, Novoa A, Mallo M. Switching axial progenitors from producing trunk to tail tissues in vertebrate embryos. Dev. Cell. 2013; 25: 451-462. https://doi.org/10.1016/j. devcel.2013.05.009 PMID: 23763947

31. Aires R, de Lemos L, Novoa A, Jurberg AD, Mascrez B, Duboule D, et al. Tail Bud Progenitor Activity Relies on a Network Comprising Gdf11, Lin28, and Hox13 Genes. Dev. Cell. 2019; 48:383-395. https:// doi.org/10.1016/j.devcel.2018.12.004 PMID: 30661984

32. Hammerle B, Tejedor FJ. A novel function of DELTA-NOTCH signalling mediates the transition from proliferation to neurogenesis in neural progenitor cells. PLoS One. 2007; 2: e1169. https://doi.org/10. 1371/journal.pone.0001169 PMID: 18000541

33. Akai J, Halley PA, Storey KG. FGF-dependent Notch signaling maintains the spinal cord stem zone. Genes Dev. 2005; 19: 2877-2887. https://doi.org/10.1101/gad.357705 PMID: 16287717

34. Sherman MS, Cohen BA. Thermodynamic state ensemble models of cis-regulation. PLoS Comp. Biol. 2012; 8: e1002407. https://doi.org/10.1371/journal.pcbi.1002407 PMID: 22479169

35. Santillan M. On the Use of the Hill Functions in Mathematical Models of Gene Regulatory Networks. Math. Modeling Nat. Phenom. 2008; 3(2): 85-97.

36. Shi W, Ma W, Xiong L, Zhang M, Tang C. Adaptation with transcriptional regulation. Sci. Rep. 2017; 7 : 42648. https://doi.org/10.1038/srep42648 PMID: 28233824 
37. Tiedemann HB, Schneltzer E, Zeiser S, Hoesel B, Beckers J, Prezmeck GK, et al. From dynamic expression patterns to boundary formation in the presomitic mesoderm. PLoS Comp Biol. 2012; 8: e04379. https://doi.org/10.1371/journal.pcbi.1002586 PMID: 22761566

38. Kiparissides A, Koutinas M, Moss T, Newman J, Pistikopoulos EM, Mantalaris A. Modelling the Delta1/ Notch1 pathway: in search of the mediator(s) of neural stem cell differentiation. PLoS One. 2011; 6: e14668. https://doi.org/10.1371/journal.pone.0014668 PMID: 21346804

39. Pogenberg V, Guichou JF, Vivat-Hannah V, Kammerer S, Perez E, Germain P, et al. Characterization of the interaction between retinoic acid receptor/retinoid $X$ receptor (RAR/RXR) heterodimers and transcriptional coactivators through structural and fluorescence anisotropy studies. J Biol Chem. 2005; 280:1625-1633. https://doi.org/10.1074/jbc.M409302200 PMID: 15528208

40. Diez del Corral R, Morales AX. The multiple roles of FGF signaling in the developing spinal cord. Front Cell Dev Biol. 2017; 5: 58. https://doi.org/10.3389/fcell.2017.00058 PMID: 28626748

41. Dubrulle J, Pourquie O. fgf8 mRNA decay establishes a gradient that couples axial elongation to patterning in the vertebrate embryo. Nature. 2004; 427: 419-422. https://doi.org/10.1038/nature02216 PMID: 14749824

42. Muller P, Rogers KW, Yu SR, Brand M, Schier AF. Morphogen transport. Development. 2013; 104: 1621-1628. https://doi.org/10.1242/dev.083519 PMID: 23533171

43. Atsuta $Y$, Takahashi Y. FGF8 coordinates tissue elongation and cell epithelialization during early kidney tubulogenesis. Development. 2015; 142: 2329-2337. https://doi.org/10.1242/dev.122408 PMID: 26130757

44. Olivera-Martinez I, Schurch N, Li RA, Song J, Halley PA, Das RM, et al. Major transcriptome re-organisation and abrupt changes in signaling, cell cycle and chromatin regulation at neural differentiation in vivo. Development. 2014; 141: 3266-3276. https://doi.org/10.1242/dev.112623 PMID: 25063452

45. Eroshkin FM, Nesterenko AM, Borodulin AV, Martynova NY, Ermakova GV, Gyoeva FK, et al. Noggin4 is a long-range inhibitor of Wnt8 signalling that regulates head development in Xenopus laveis. Sci. Rep. 2016; 6: 23049. https://doi.org/10.1038/srep23049 PMID: 26973133

46. Niederreither K, McCaffrey P, Dräger UC, Chambon P, Dollé P. Restricted expression and retinoic acidinduced downregulation of the retinaldehyde dehydrogenase type $2(\mathrm{RALDH}-2)$ gene during mouse development. Mech. Dev. 1997; 62: 67-78. https://doi.org/10.1016/s0925-4773(96)00653-3 PMID: 9106168

47. White RJ, Nie Q, Lander AD, Schilling TF. Complex regulation of cyp26a1 creates a robust retinoic acid gradient in the zebrafish embryo. PLoS Biol. 2007; 5: e304. https://doi.org/10.1371/journal.pbio. 0050304 PMID: 18031199

48. Muller CW, Herrmann BG. Crystallographic structure of the T domain-DNA complex of the Brachyury transcription factor. Nature. 1997; 389: 884-888. https://doi.org/10.1038/39929 PMID: 9349824

49. Hou L, Srivastava $Y$, Jauch R. Molecular basis for the genome engagement by Sox proteins. Semin Cell Dev Biol. 2017; 63: 2-12. https://doi.org/10.1016/j.semcdb.2016.08.005 PMID: 27521520

50. Gregory PA, Gardner-Stephen DA, Rogers A, Michael MZ, Mackenzie PI. The caudal-related homeodomain protein $\mathrm{Cdx} 2$ and hepatocyte nuclear factor 1 alpha cooperatively regulate the UDP-glucuronosyltransferase 2B7 gene promoter. Pharmacogenet Genomics. 2006; 16: 527-536. https://doi.org/10. 1097/01.fpc.0000215068.06471.35 PMID: 16788384

51. Singh S, Stellrecht CM, Tang HK, Saunders GF. Modulation of PAX6 homeodomain function by the paired domain. J Biol Chem. 2000; 275:17306-17313. https://doi.org/10.1074/jbc.M000359200 PMID: 10747901

52. Gradwohl G, Fode C, Guillemot F. Restricted expression of a novel murine atonal-related bHLH protein in undifferentiated neural precursors. Dev. Biol. 1996; 180:227-241. https://doi.org/10.1006/dbio.1996. 0297 PMID: 8948587

53. Gaunt SJ, Drage D, Trubshaw RC. cdx4/lacZ and cdx2/lacZ protein gradients formed by decay during gastrulation in the mouse. Int J Dev Biol. 2005; 49: 901-908. https://doi.org/10.1387/ijdb.052021sg PMID: 16281167

54. Lunn JS, Fishwick KJ, Halley PA, Storey KG. A spatial and temporal map of FGF/Erk1/2 activity and response repertoires in the early chick embryo. Dev. Biol. 2007; 302: 536-552. https://doi.org/10.1016/ j.ydbio.2006.10.014 PMID: 17123506

55. Vitobello A, Ferretti E, Lampe X, Vilain N, Ducret S, Ori M, et al. Hox and Pbx factors control retinoic acid synthesis during hindbrain segmentation. Dev. Cell. 2011; 20: 469-482. https://doi.org/10.1016/j. devcel.2011.03.011 PMID: 21497760

56. Kumar S, Duester G. Retinoic acid controls body axis extension by directly repressing Fgf8 transcription. Development. 2014; 141: 2972-2977. https://doi.org/10.1242/dev.112367 PMID: 25053430 
57. Cunningham TJ, Colas A, Duester G. Early molecular events during retinoic acid induced differentiation of neuromesodermal progenitors. Biol. Open. 2016; 5: 1821-1833. https://doi.org/10.1242/bio.020891 PMID: 27793834

58. Bel-Vialar S, Itasaki N, Krumlauf R. Initiating Hox gene expression: in the early chick neural tube differential sensitivity to FGF and RA signaling subdivides the HoxB genes in two distinct groups. Development. 2002; 129: 5103-5115. PMID: 12399303

59. Takemoto $\mathrm{T}$, Uchikawa M, Kamachi $\mathrm{Y}$, Kondoh H. Convergence of Wnt and FGF signals in the genesis of posterior neural plate through activation of the Sox2 enhancer N-1. Development. 2006; 133: 297306. https://doi.org/10.1242/dev.02196 PMID: 16354715

60. Nordstrom U, Maier E, Jessell TM, Edlund T. An early role for WNT signaling in specifying neural patterns of $\mathrm{Cdx}$ and Hox gene expression and motor neuron subtype identity. PLoS Biology. 2006; 4: e252. https://doi.org/10.1371/journal.pbio.0040252 PMID: 16895440

61. Tamashiro DA, Alarcon VB, Marikawa Y. Nkx1-2 is a transcriptional repressor and is essential for the activation of Brachyury in P19 mouse embryonal carcinoma cell. Differentiation. 2012; 83: 282-292. https://doi.org/10.1016/j.diff.2012.02.010 PMID: 22475651

62. Novitch BG, Wichterle H, Jessell TM, Sockanathan S. A requirement for retinoic acid-mediated transcriptional activation in ventral neural patterning and motor neuron specification. Neuron. 2003; 40: $81-$ 95. https://doi.org/10.1016/j.neuron.2003.08.006 PMID: 14527435

63. Sasai N, Kutejova E, Briscoe J. Integration of signals along orthogonal axes of the vertebrate neural tube controls progenitor competence and increases cell diversity. PLoS Biology. 2014; 12: e1001907. https://doi.org/10.1371/journal.pbio.1001907 PMID: 25026549

64. Pownall ME, Isaacs HV, Slack JM. Two phases of Hox gene regulation during early Xenopus development. Cur. Biol. 1998; 8: 673-676. https://doi.org/10.1016/s0960-9822(98)70257-x PMID: 9635197

65. Oates AC, Morelli LG, Ares S. Patterning embryos with oscillations: structure, function and dynamics of the vertebrate segmentation clock. Development. 2012; 139: 625-639. https://doi.org/10.1242/dev. 063735 PMID: 22274695

66. Young T, Rowland JE, van de Ven C, Bialecka M, Novoa A, Carapuco M, et al. Cdx and Hox genes differentially regulate posterior axial growth in mammalian embryos. Dev. Cell. 2009; 17: 516-526. https:// doi.org/10.1016/j.devcel.2009.08.010 PMID: 19853565

67. Isaacs HV, Pownall ME, Slack JM. Regulation of Hox gene expression and posterior development by the Xenopus caudal homologue Xcad3. EMBO J. 1998; 17: 3413-3427. https://doi.org/10.1093/emboj/ 17.12.3413 PMID: 9628877

68. Li Y, Tzatzalos E, Kwan KY, Grumet M, Cai L. Transcriptional Regulation of Notch1 Expression by Nkx6.1 in Neural Stem/Progenitor Cells during Ventral Spinal Cord Development. Sci. Reports. 2016; 6: 38665. https://doi.org/10.1038/srep38665 PMID: 27924849

69. Tsimring LS. Noise in biology. Rep Prog Phys. 2014; 77: 026601. https://doi.org/10.1088/0034-4885/ 77/2/026601 PMID: 24444693

70. Bergman A, Siegal ML. Evolutionary capacitance as a general feature of complex gene networks. Nature. 2003; 424: 549-552. https://doi.org/10.1038/nature01765 PMID: 12891357

71. Goto H, Kimmey SC, Row RH, Matus DQ, Martin BL. FGF and canonical Wnt signaling cooperate to induce paraxial mesoderm from tailbud neuromesodermal progenitors through regulation of a two-step epithelial to mesenchymal transition. Development. 2017; 144: 1412-1424. https://doi.org/10.1242/dev 143578 PMID: 28242612

72. Martin BL, Kimelman D. Brachyury establishes the embryonic mesodermal progenitor niche. Genes Dev. 2010; 24: 2778-2783. https://doi.org/10.1101/gad.1962910 PMID: 21159819

73. Takada S, Fujimori S, Shinozuka T, Takada R, Mii Y. Differences in the secretion and transport of Wnt proteins. J Biochem. 2017; 161: 1-7. https://doi.org/10.1093/jb/mvw071 PMID: 28053142

74. Amin S, Neijts R, Simmini S, van Rooijen C, Tan SC, Kester L, et al. Cdx and T Brachyury Co-activate Growth Signaling in the Embryonic Axial Progenitor Niche. Cell Rep. 2016; 17: 3165-3177. https://doi. org/10.1016/j.celrep.2016.11.069 PMID: 28009287

75. Castillo HA, Cravo RM, Azambuja AP, Simoes-Costa MS, Sura-Trueba S, Gonzalez J, et al. Insights into the organization of dorsal spinal cord pathways from an evolutionarily conserved raldh2 intronic enhancer. Development. 2010; 137: 507-518. https://doi.org/10.1242/dev.043257 PMID: 20081195 